\title{
Restricted Neural Plasticity in Vestibulospinal Pathways after Unilateral Labyrinthectomy as the Origin for Scoliotic Deformations
}

\author{
François M. Lambert, ${ }^{1}$ David Malinvaud, ${ }^{1,2}$ Maxime Gratacap, ${ }^{1}$ Hans Straka, ${ }^{3 *}$ and Pierre-Paul Vidal ${ }^{1 \star}$ \\ ${ }^{1}$ Centre d'Etude de la SensoriMotricité, Centre National de la Recherche Scientifique Unité Mixte de Recherche 8194, Université Paris Descartes, 75006 \\ Paris, France, ${ }^{2}$ Département d'Oto-Rhino-Laryngologie et de Chirurgie Cervico-Faciale, Hôpital Européen Georges Pompidou, 75015 Paris, France, and \\ ${ }^{3}$ Department Biology II, Ludwig-Maximilians-University Munich, 82152 Planegg, Germany
}

\begin{abstract}
Adolescent idiopathic scoliosis in humans is often associated with vestibulomotor deficits. Compatible with a vestibular origin, scoliotic deformations were provoked in adult Xenopus frogs by unilateral labyrinthectomy (UL) at larval stages. The aquatic ecophysiology and absence of body-weight-supporting limb proprioceptive signals in amphibian tadpoles as a potential sensory substitute after UL might be the cause for a persistent asymmetric descending vestibulospinal activity. Therefore, peripheral vestibular lesions in larval Xenopus were used to reveal the morphophysiological alterations at the cellular and network levels. As a result, spinal motor nerves that were modulated by the previously intact side before UL remained permanently silent during natural vestibular stimulation after the lesion. In addition, retrograde tracing of descending pathways revealed a loss of vestibular neurons on the ipsilesional side with crossed vestibulospinal projections. This loss facilitated a general mass imbalance in descending premotor activity and a permanent asymmetric motor drive to the axial musculature. Therefore, we propose that the persistent asymmetric contraction of trunk muscles exerts a constant, uncompensated differential mechanical pull on bilateral skeletal elements that enforces a distortion of the soft cartilaginous skeletal elements and bone shapes. This ultimately provokes severe scoliotic deformations during ontogenetic development similar to the human syndrome.
\end{abstract}

\section{Introduction}

Skeletal deformations such as adolescent idiopathic scoliosis (AIS) are characterized by postural deficits and perturbations of locomotor activity, mostly due to malformation of the vertebral column (Weinstein et al., 2008). The multifactorial origin of AIS and its unknown etiopathogeny and various dysfunctions in different hormonal and molecular pathways (Ahn et al., 2002; Moreau et al., 2004; Cheung et al., 2008; Burwell et al., 2009; Machida et al., 2009) render a clear relationship with a particular cause problematic. The unclear origin and sequence of morphophysiological events that lead to scoliotic deformations in human patients is matched by the multitude of animal models that attempt to reproduce the induction and/or progression of skeletal abnormalities (Barrios et al., 1987; O'Kelly et al., 1999; Cheung et al., 2005; Fagan et al., 2009; Lambert et al., 2009).

\footnotetext{
Received Oct. 4, 2012; revised Jan. 7, 2013; accepted Feb. 20, 2013.

Author contributions: F.M.L., H.S., and P.-P.V. designed research; F.M.L., D.M., and M.G. performed research; D.M. and M.G. contributed unpublished reagents/analytic tools; F.M.L. analyzed data; F.M.L., H.S., and P.-P.V. wrote the paper.

This study was supported and funded by the Fondation Yves Cotrel, the Fondation pour la Recherche Médicale, and the Centre National de la Recherche Scientifique. We thankS. Lecolles and Drs. B. Della Gaspera, C.Chanoine, and M. Beraneck for their assistance with this study.

*H.S. and P.-P.V. contributed equally to this work.

Correspondence should be addressed to Dr. Hans Straka, Biocenter-Martinsried, Department Biology II, LudwigMaximilians-University Munich, Germany. E-mail: straka@Imu.de.

DOI:10.1523/JNEUROSCI.4842-12.2013

Copyright $\odot 2013$ the authors $\quad 0270-6474 / 13 / 336845-12 \$ 15.00 / 0$
}

In many AIS patients, the structural malformations are accompanied by a vestibular dysfunction that affects gaze and posture control and locomotor skills (Jensen and Wilson, 1979; Sahlstrand and Petruson, 1979; Sahlstrand et al., 1979; WienerVacher and Mazda, 1998; Rousie et al., 1999; Manzoni and Miele, 2002; Mallau et al., 2007; Haumont et al., 2011; Shi et al., 2011). However, it is unclear whether these vestibular deficits are caused by the skeletal deformations as a response to the adopted asymmetric body posture or if the scoliotic syndrome is the consequence of a principal bilateral vestibular imbalance. The latter possibility was substantiated by findings in Xenopus laevis, an amphibian species established previously as a model for developmental and lesion-induced plasticity of vestibular reflexes (Horn and Rayer, 1978; Horn et al., 1986a,1986b; Rayer and Horn, 1986). After unilateral labyrinthectomy (UL) at larval stages, adult Xenopus frogs continue to exhibit a postural asymmetry and skeletal deformation with many characteristics reminiscent of human AIS (Lambert et al., 2009). This induction of scoliotic distortions was interpreted as failure to postlesionally readjust the imbalanced bilateral vestibular signals by body-weightsupporting limb proprioception in these permanently aquatic animals. The unusual character of the compensation in Xenopus (Horn, 1981; Rayer et al., 1983; Lambert et al., 2009) is at variance with the classical postural recovery after UL in terrestrial vertebrates (Dieringer, 1995) and is a likely key element that makes this species well suited for studying morphophysiological alterations related to the manifestation of skeletal deformations. Accordingly, a putatively common denominator that might 
reconcile the various, apparently unrelated origins of AIS-like skeletal syndromes in different animal models is the induction of a permanently imbalanced activity in descending neuronal pathways. This would cause an asymmetric, tonic contraction of bilateral axial muscles and a continuous pull on the mostly cartilaginous skeletal elements during early ontogeny.

To reveal neural changes and functional consequences after UL in larval Xenopus, experiments were conducted on semi-intact in vitro preparations during passively induced vestibular stimulation and spontaneous locomotor activity, along with structural analyses of neuronal and skeletal elements. The results suggest that a permanently imbalanced activity in descending brainstem-spinal pathways, including vestibulospinal projections, causes the observed skeletal distortions in adult frogs.

\section{Materials and Methods}

Animals. Experiments were conducted on $64 X$. laevis tadpoles of either sex at developmental stage 54-57 (Nieuwkoop and Faber, 1994) and complied with the Principles of Animal Care (National Institutes of Health publication \#86-23 revised 1985). Permission for the experiments was granted by the Direction départementale des services vétérinaires de Paris (75-1641) and approved by the Comité d'Ethique en matière d'Expérimentation Animale Paris Descartes (\#CEEA34.PPV.001.13). Animals were obtained from an authorized supplier (Centre de Ressources Biologiques Xénopes, UMS 3387, CNRS) and kept in the laboratory in filtered water at $18^{\circ} \mathrm{C}$ until use for experimentation. After determination of the developmental stage, tadpoles of stage 54 and 55 were subjected to UL ( $n=41$; Fig. $1 A_{1}-A_{4}$ ). The surgery was performed under general anesthesia with $0.05 \%$ MS-222 (3-aminobenzoic acid ethyl ester; Sigma-Aldrich) in frog Ringer's solution containing the following (in $\mathrm{mm}$ ): $75 \mathrm{NaCl}, 25 \mathrm{NaHCO} 3,2 \mathrm{CaCl} 2,2 \mathrm{KCl}, 0.5$ $\mathrm{MgCl} 2$, and 11 glucose, $\mathrm{pH}$ 7.4. In all cases, the left otic capsule was opened and labyrinthine end organs including vestibular nerve branches and the ganglion of Scarpa were removed under direct visual control (Fig. $1 A_{1}-A_{4}$ ).

Electrophysiological experiments. Recording of central nervous activity was made in isolated head preparations in vitro of intact stage 55-57 Xenopus tadpoles and at various postlesional periods after UL performed at stage 54 or 55 . For isolation of the brain/spinal cord, animals were deeply anesthetized in $0.05 \%$ MS-222 and decapitated, leaving the dorsal part of the skull with the brainstem and rostral spinal cord intact (Lambert et al., 2008, 2012). After opening of the skull by a dorsal approach, the forebrain was removed and both optic nerves were severed. In addition, all cranial and spinal motor nerves were transected either close to the root exit or at the innervation site of the respective muscles. In contrast, the otic capsule with all vestibular end organs remained intact and connected to the brain by the VIII ${ }^{\text {th }}$ nerve. Preparations were rinsed in fresh Ringer's solution, transferred to a Sylgard-lined Petri dish (volume $5 \mathrm{ml}$ ), and perfused continuously with oxygenated Ringer's solution at a rate of $1.5-2.1 \mathrm{ml} / \mathrm{min}$. The temperature in the chamber was elec-
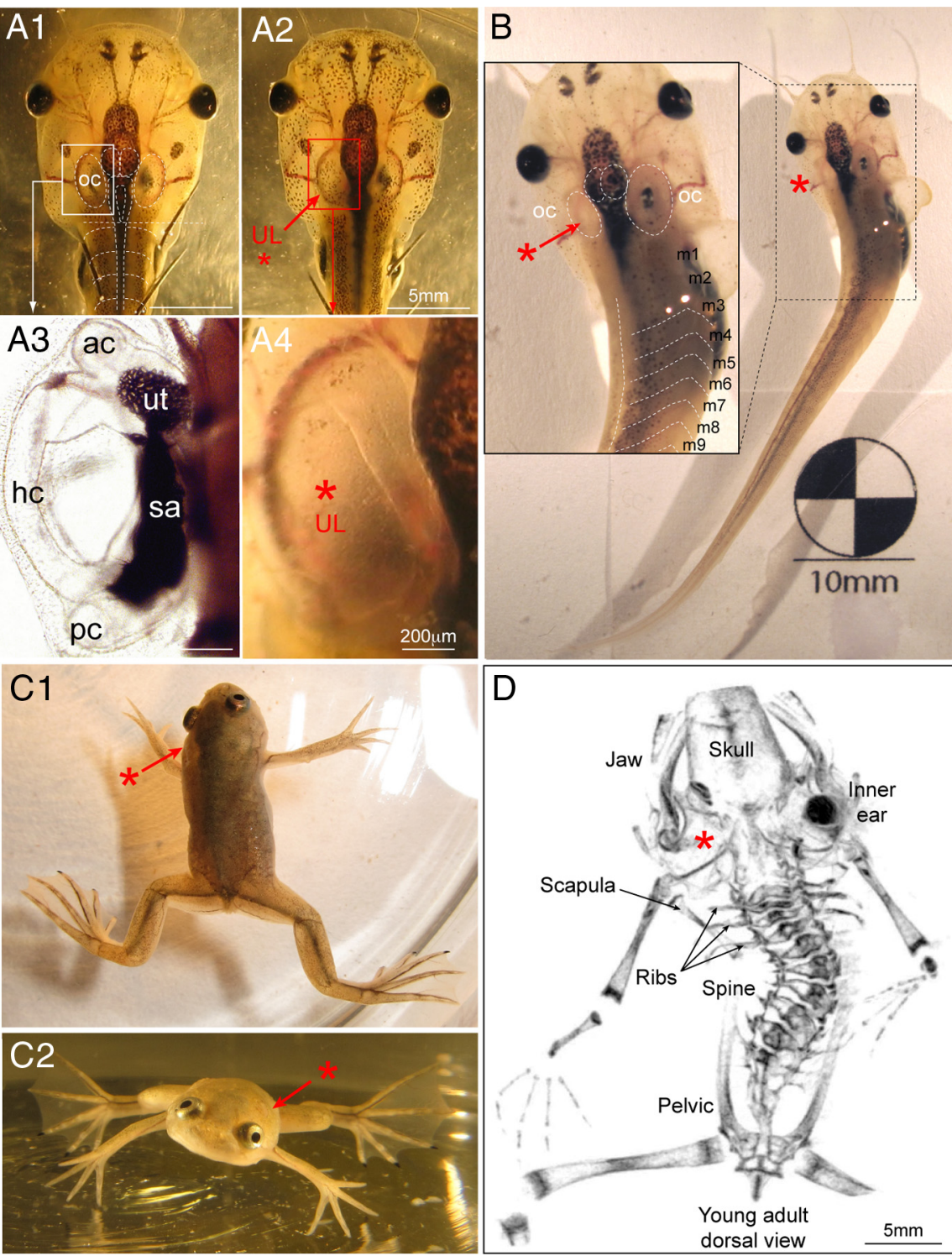

Figure 1. Induction of postural asymmetry and skeletal distortion by UL. $A, B$, Removal of all labyrinthine end organs $\left(A_{1}, A_{3}\right)$ from the otic capsule on the left side in a stage 55 tadpole $\left(\boldsymbol{A}_{2} \boldsymbol{A}_{4}\right)$ causes a persistent leftward bending of the body/tail, during the 66) subjected to a UL at larval stage 55 , illustrating the typical twisted body shape and asymmetric limb positions. $D$

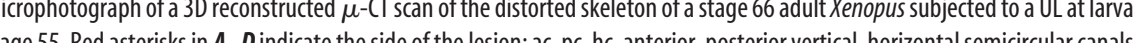
stage 55. Red asterisks in $A-D$ indicate oc, otic capsule; sa, saccule; ut, utricle.

tronically controlled and maintained at $17 \pm 0.1^{\circ} \mathrm{C}$. Multiple-unit discharge of a bilateral pair of spinal ventral roots (SVr's) between segments 6 and 10 during spontaneous fictive swimming (Combes et al., 2004; Böser and Horn, 2006) and during natural activation of vestibular end organs on a motion simulator, as well as the extraocular motor nerve innervating the lateral rectus (LR) muscle, were recorded with individually adjusted glass suction microelectrodes.

Natural activation of semicircular canal and otolith organs was provided by mounting the recording chamber onto a computer-controlled, motorized two-axis turntable with the animal centered in the horizontal and vertical rotation axes (Lambert et al., 2008). The motion stimuli consisted of vertical-axis (frequency: $0.5-1 \mathrm{~Hz}$; table velocity: $\pm 30-$ $60^{\circ} / \mathrm{s}$ ) and horizontal roll-axis (frequency: $0.1 \mathrm{~Hz}$; table position: $\pm 10^{\circ}$ ) sinusoidal rotations of the isolated preparation. The SVr and LR extraocular nerve discharges were recorded (Ext 10-2F; NPI Electronics), digitized $(10 \mathrm{kHz})$, stored on a computer, and analyzed offline (CED 
1401, Spike 2; Cambridge Electronic Design). The depth of discharge modulation was determined by calculating the difference between the minimum and maximum peak rates of the averaged discharge over one cycle at a given frequency and velocity/position magnitude.

Neural tracing in semi-intact preparations. Xenopus tadpoles (stage 5557) were anesthetized in $0.05 \%$ MS-222 and transferred into oxygenated, ice-cold frog Ringer's solution. After decapitation and opening of the skull by a dorsal approach and removal of the forebrain and choroid plexus above the $\mathrm{IV}^{\text {th }}$ ventricle, the Ringer's solution was temporarily removed and crystals of Alexa Fluor 488, 546, and 647 dextran (10,000 MW; Invitrogen) were separately applied in different combinations to both sides of the spinal cord at the level of segments 1-2 (Straka et al., 2001). For labeling of VIII ${ }^{\text {th }}$ nerve afferent fibers, the otic capsule was opened, labyrinthine end organs were removed, and crystals of Alexa Fluor 546 dextran were applied for $10-15$ min to the VIII ${ }^{\text {th }}$ nerve distal to the ganglion of Scarpa or to the stump of the previously sectioned VIII ${ }^{\text {th }}$ nerve on the ipsilesional side at the entrance into the brainstem. After tracer application, surplus dye was removed with excess Ringer's solution and preparations were incubated for $24 \mathrm{~h}$ at $10^{\circ} \mathrm{C}$ in oxygenated frog Ringer's solution containing $0.01 \%$ MS- 222 . Thereafter, brains were removed from the skull, fixed in $4 \%$ paraformaldehyde in $0.1 \mathrm{M}$ phosphate buffer (PB) for $24 \mathrm{~h}$, cleared in $25 \%, 50 \%$ and $100 \%$ glycerol (SigmaAldrich), mounted on slides, and coverslipped with $100 \%$ glycerol. Some preparations were embedded in $4 \%$ low-melting agarose (SigmaAldrich) in $0.1 \mathrm{M} \mathrm{PB}$ and cut coronally in $80 \mu \mathrm{m}$ sections on a Leica Vibratome. Whole-mount preparations and coronal sections were analyzed by laser scanning confocal microscopy (LSM 510; Zeiss) at wavelengths of 488,543 , and $643 \mathrm{~nm}$. Stacks of 10-20 confocal images with 5-10 $\mu \mathrm{m} z$-axis intervals were generated with a $10 \times / 0.5$ and a $20 \times / 0.5$ objective. The images in Figures 6, 7, and 8 were produced by horizontal projections of entire stacks with artificial fluorescent colors using the freeware LSM Image Browser 4.2 and Carl Zeiss microscopy and imaging software. Quantification of neuronal numbers was obtained by combining both projection views and stack images with LSM Image Browser to avoid double cell counting.

Calcein labeling. In vivo cartilage- and bone-labeling protocols were adapted from a technique described previously for zebrafish (Du et al., 2001). Animals between stages 55 and 65 were incubated for $2 \mathrm{~h}$ in a $0.05 \%$ calcein (Sigma-Aldrich) solution in filtered tank water. After rinsing four times for $30 \mathrm{~min}$ in tank water, tadpoles and young adults were anesthetized in an aqueous solution of $0.01 \%$ MS-222 and photographed from the dorsal side with a QImaging RoHS digital camera mounted onto a stereomicroscope (C-PS SMZ1000; Nikon). Images were processed with QCapture Pro 6 software from QImaging (www. qimaging.com).

Histological preparations. After anesthesia in $0.05 \%$ MS-222, tadpoles were fixed in $4 \%$ neutral buffered paraformaldehyde for $2 \mathrm{~d}$ at room temperature, and then rinsed briefly in $0.1 \mathrm{M}$ PB. Tails were embedded in paraffin and cut coronally in $10 \mu \mathrm{m}$ sections. For anatomical identification of muscle and cartilage tissue, sections were first dehydrated in a series of increasing alcohol concentrations (70\%, 90\%, 96\%, 100\%), followed by a staining with Alcian blue and hematoxylin-eosin. Before the staining, samples were photobleached for $3-12 \mathrm{~h}$ in $0.3 \% \mathrm{H}_{2} \mathrm{O}_{2}$ and $5 \%$ $\mathrm{KOH}$ at room temperature. Consecutive sections of tails were photographed on a microscope (BX61; OLYMPUS) with a Q Imaging RETIGA 200R Fast1394 camera. Images were cropped using Adobe Photoshop, aligned with ImageJ software for UNIX, morphed with Morph Age software for Mac OSX, and assembled using Final Cut Pro.

Statistics. Statistical differences between data obtained from two groups of animals or from the left and right side in a given group were calculated with nonparametric statistical tests. For comparison of data obtained from controls and the individual groups of animals after a specific postlesional survival time, the Mann-Whitney $U$ test for unpaired parameters was used. For comparison of data obtained from the left and right side in a given group of animals (e.g., the number of retrogradely labeled vestibular neurons or peak firing rates of spinal or extraocular nerve roots during rotation), the Wilcoxon signed-rank test for paired parameters was used.

\section{Results}

\section{Induction of postural deficits and skeletal deformations} after UL

Unilateral removal of all vestibular end organs under direct visual control (Fig. $1 A_{1}-A_{4}$ ) in Xenopus tadpoles during the second half of the premetamorphic larval period ( $>$ stage 54 ) caused a typical curvature of the head/body toward the ipsilesional side after the lesion (Fig. 1B). This posture was adopted immediately after the $\mathrm{UL}$ when the anesthesia had ceased. In addition, the bending of the body along the longitudinal axis persisted and was accompanied by a constant rolling toward the ipsilesional side during swimming activity (Horn, 1981). Mechanically, the bending in the horizontal plane of the body appeared to be caused by an asymmetric contraction of the bilateral axial musculature that essentially involved the first 10 myotomes in the larvae (Fig. 1B). The postural asymmetry, induced at this relatively late larval stage, in contrast to a lesion in younger tadpoles (Horn and Rayer, 1978; Rayer et al., 1983; <stage 46), was retained after metamorphosis into adult frogs (Fig. 1C). Moreover, the twisted body shape in these animals was now accompanied by asymmetric limb positions due to a differential flexion and extension of forelimbs and hindlimbs on the ipsilesional and contralesional side, respectively (Fig. 1C), reflecting the postural syndrome after UL in this species described and illustrated previously (Horn, 1981; Rayer et al., 1983). The persistent behavioral asymmetry in body posture in adult frogs after a preceding UL at larval stages was found to be paralleled by scoliosis-like deformations of the skeleton, as evidenced from 2D X-ray radiography and 3D reconstructions of $\mu$-CT scans of the structural elements (Fig. 1D) as described previously in more detail (Lambert et al., 2009).

\section{Development of skeletal deformations after UL}

The onset and progression of the skeletal deformations was monitored qualitatively by specific staining of cartilaginous and osseous elements with calcein complemented by a differential colorimetric staining to distinguish cartilage from other types of tissue (Fig. 2). Control animals with a normal body posture and limb position $(n=5)$ were stained repetitively with calcein in several successive premetamorphic and postmetamorphic stages, respectively (Fig. $2 A_{1}$ ). In vivo whole-body fluorescence imaging of these controls revealed a nearly bilateral symmetric formation and arrangement of cartilaginous/osseal vertebral elements in the rostral tail (larvae) and trunk region (adult) between developmental stage 55 and 64 (Fig. $2 A_{1}$ ). The formation of cartilaginous tissue is a first step in the development of individual vertebrae and was followed by a progressive ossification process that generated the bony elements of the future spine during the observation period of $\sim 45 \mathrm{~d}$. The establishment of bilateral symmetric vertebrae in controls was further verified by differential staining of cartilage and surrounding tissue with Alcian blue and hematoxylin-eosin $\left(n=3\right.$; Fig. $\left.2 B_{1}\right)$. Reconstruction of the vertebral shape from consecutive cross-sections of the rostral tail region confirmed an approximately left-right symmetrical arrangement of the vertebral elements in control animals (Fig. 2 $C_{1}$ ).

After UL at stage $55(n=7)$, all Xenopus larvae continued their ontogenetic development and completed metamorphosis into young adults within a similar time period as control animals. However, in contrast to controls, in vivo fluorescence imaging of calcein-stained skeletal elements performed between the UL and stage 64 up to three times at progressively older developmental stages showed severe distortions of the vertebrae in the tail region of the larvae and the trunk region of adults (Fig. $2 A_{2}$, yellow 

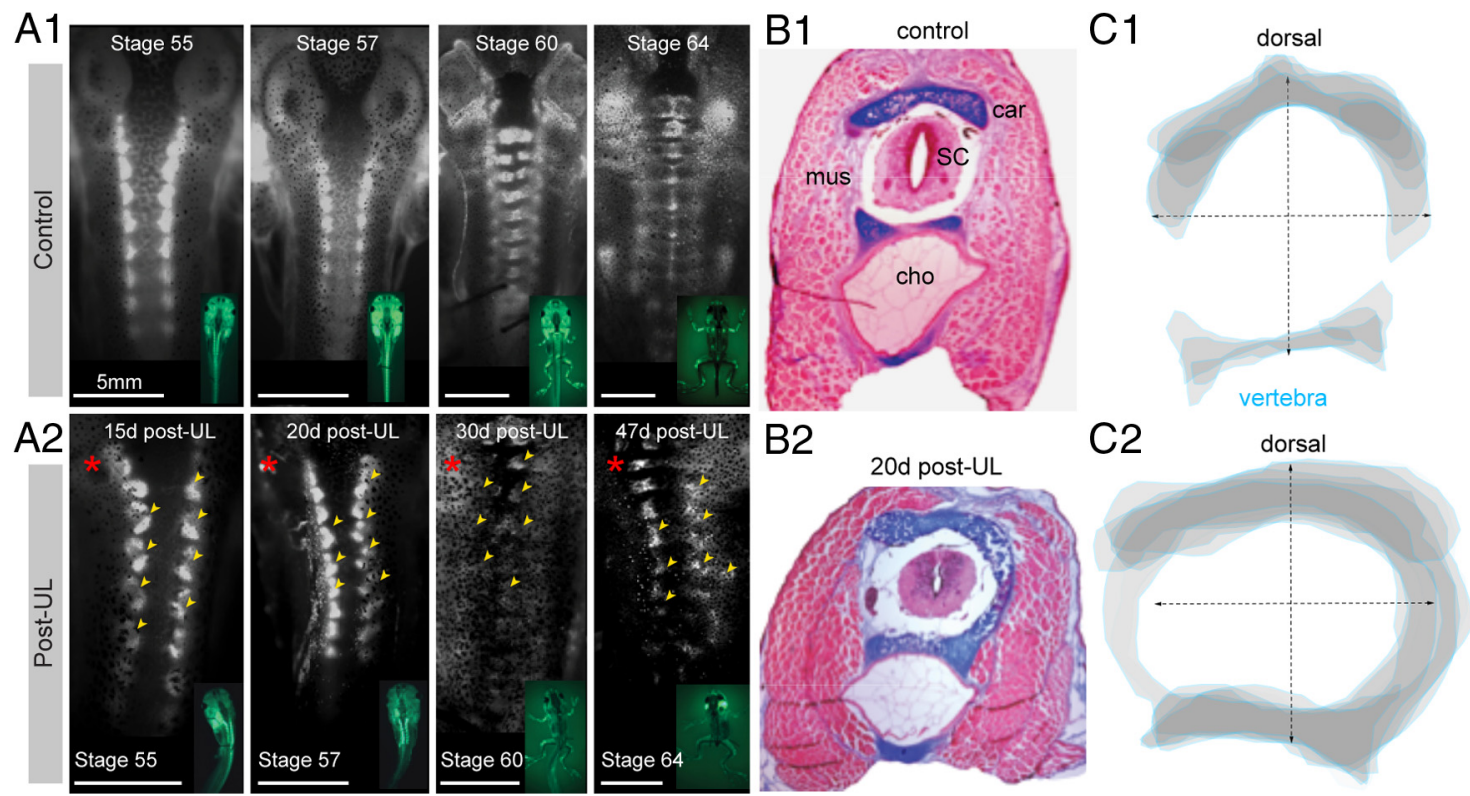

Figure 2. Structural deformations of individual vertebrae after UL. $\boldsymbol{A}$, Top view of calcein-stained cartilaginous/bony elements of the vertebral column at subsequent stages of premetamorphic and postmetamorphic development in controls $\left(\boldsymbol{A}_{1}\right)$ and after $\mathrm{UL}\left(\boldsymbol{A}_{2}\right.$, Post-UL) at different postlesional intervals (15- $\left.47 \mathrm{~d}\right)$; insets show the respective developmental stages; yellow arrowheads and red asterisks indicate deformations of the vertebral column and side of the UL, respectively. $\boldsymbol{B}$, Cross-section (10 $\mu \mathrm{m})$ through the rostral tail region at the level of myotome 4 in a stage 57 control tadpole $\left(\boldsymbol{B}_{1}\right)$ and 20 d post-UL $\left(\boldsymbol{B}_{2}\right)$; specific colorimetric staining of cartilage with Alcian blue and other tissue with hematoxilin-eosin differentiated vertebral elements such as cartilage (car), muscle (mus), spinal cord (sc), and the chorda dorsalis (cho). $\boldsymbol{C}$, Stacked schematic outlines of cross-sectioned cartilaginous vertebral tissue at the level of myotome 4 (blue lines) of a control ( $\boldsymbol{C}_{1}$ ) and $20 \mathrm{~d}$ post-UL $\left(\boldsymbol{C}_{2}\right)$; data are from the material shown in $\boldsymbol{B}_{1}$ and $\boldsymbol{B}_{2}$, respectively, and represent a superimposed overlay of 10 successive $10 \mu \mathrm{m}$ thick sections centered on the spinal cord.

arrowheads). Qualitatively, the earliest noticeable cartilage deformation occurred $\sim 15 \mathrm{~d}$ after the lesion. Even though the magnitude and specific direction of the deformation of individual vertebrae varied between different animals, as described previously (Lambert et al., 2009), the common deviation from control tissue included bilateral asymmetric positions of cartilaginous structures and abnormal cartilage growth (Fig. $2 \mathrm{~A}_{2}$ ). A differential tissue staining with Alcian blue in stage 57 larvae $(n=3$; Fig. $2 B_{2}$ ) confirmed the asymmetric formation of vertebral elements in the rostral tail region (myotome 1-10), corresponding to the future trunk of adults. The reconstructed overlay of cartilaginous vertebrae from a cross-sectioned tail at the level of myotome 4 at $20 \mathrm{~d}$ postlesion confirmed that the bilateral symmetric arrangement was distorted by an abnormal lateral growth (Fig. 2 $C_{2}$ ) that resulted in a spatial rearrangement toward a rostrocaudally oblique orientation at each segment of the vertebral column. The apparent malformation of the cartilaginous/osseous tissue early after UL at larval stages suggests that the curvature of the vertebral column and the deformation of vertebral elements is initiated before metamorphosis and thus before skeletal ossification.

\section{Persistent asymmetric activity in vestibular-related descending pathways}

Based on previous results (Lambert et al., 2009) and on the present morphological data, the key assumption for provoking skeletal deformations in Xenopus after a preceding UL is the induction of a tonic asymmetric activity in descending pathways to the spinal cord that is not compensated by postlesional plasticity and thus remains permanent provided the lesion is induced in tadpoles older than stage 46 (Rayer et al., 1983). Therefore, potential bilateral asymmetries in spinal motor responses during dynamic vestibular stimulation were tested in vitro in semi-intact preparations of larval Xenopus at $15 \mathrm{~d}$ (stage 55: $n=2$; stage 56: $n=3$ ) and 6 weeks (stage 55: $n=2$; stage 56: 5; stage 57: $n=5$ ), which allowed natural activation of vestibulomotor pathways by vertical- and horizontal-axis rotation detected by functionally intact semicircular canal and otolith organs on the contralesional, intact side (Lambert et al., 2008; Straka and Simmers, 2012).

In the three different groups (controls, immediately post-UL, and 6 weeks post-UL), the motor activity in bilateral SVr 6-10 was evoked by head rotation around the yaw and roll axes on a turntable (Fig. $3 A_{1}$ ). These stimuli activated a spatiotemporally characteristic discharge modulation in the latter nerve roots (Fig. 3, Fig. 4). In control animals (stage 55 and 57: $n=2$ each), a sinusoidal vertical-axis rotation at $1.0 \mathrm{~Hz}( \pm 60 \%$ s peak velocity) caused a symmetric multiple-unit discharge modulation in the left and right SVr with opposite phase relations, respectively (Fig. $3 B$, black traces). The horizontal semicircular canal-driven discharge increased during contraversive rotations with a peak discharge frequency on either side that depended on stimulus amplitude and reached up to $\sim 40$ spikes/s (mean \pm SE, $40.7 \pm$ $6.0 ; n=6$ ) at $1 \mathrm{~Hz}$ and $\sim 30$ spikes/s (mean $\pm \mathrm{SE}, 28.2 \pm 2.4$ spikes/s; $n=6$ ) at $0.5 \mathrm{~Hz}$ (Fig. $3 C, D$ ). A similar symmetric discharge modulation of the SVr was activated during lowfrequency sinusoidal rotation $(0.1 \mathrm{~Hz})$ in the roll plane in control animals (stages 55 and 57: $n=2$ each; stage 56: $n=1$ ) with bilaterally intact vestibular end organs (Fig. $4 A_{1}, A_{2}$, black traces). Given the low stimulus frequency in the roll plane, the latter stimulus predominantly activated utricular pathways that caused a distinct, but in this rotational plane only moderate, multipleunit peak discharge modulation of $10-15$ spikes/s (mean \pm SE, $11.6 \pm 2.1 ; n=5)$ with opposite phase relations in the bilateral SVr (Fig. $4 B, C$ ).

After UL on the left side (Fig. $3 A_{2}$ ), the major difference with respect to controls was the marked loss of the vestibular-evoked increase of SVr discharge on the right, contralesional side regardless of stimulus plane or amplitude (Fig. $3 B$, Fig. $4 A_{2}$, green 
A1
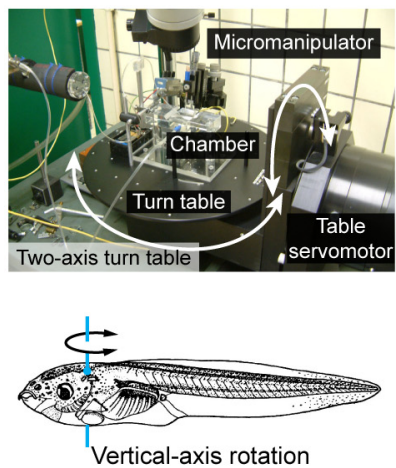

A2

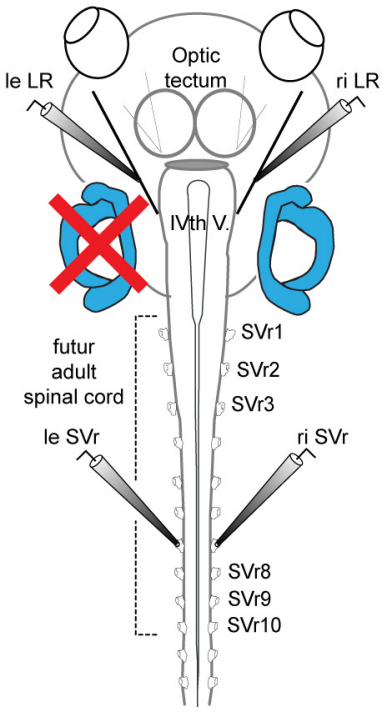

B

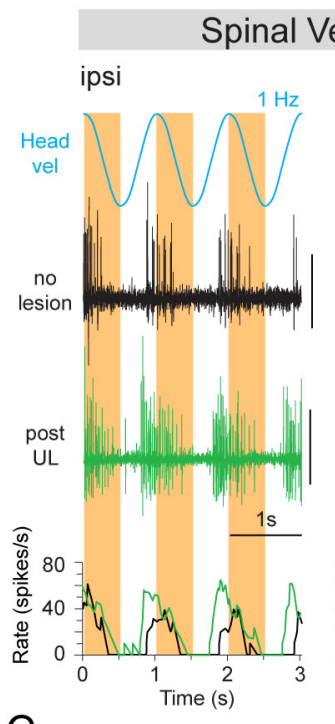

C

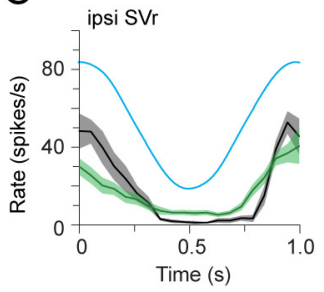

D

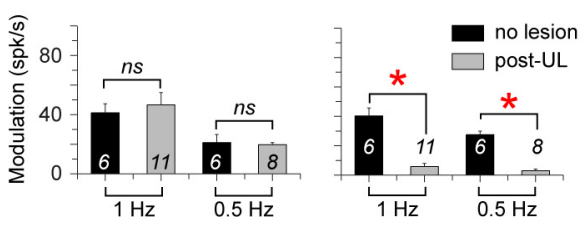

E

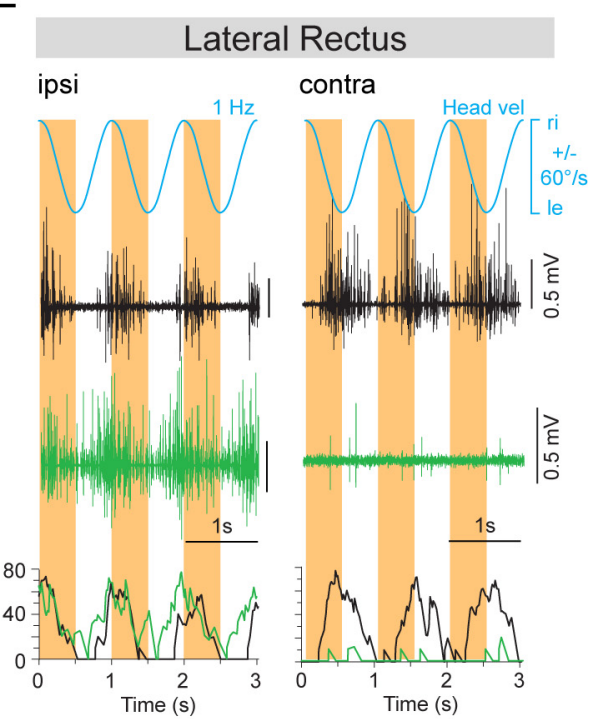

F
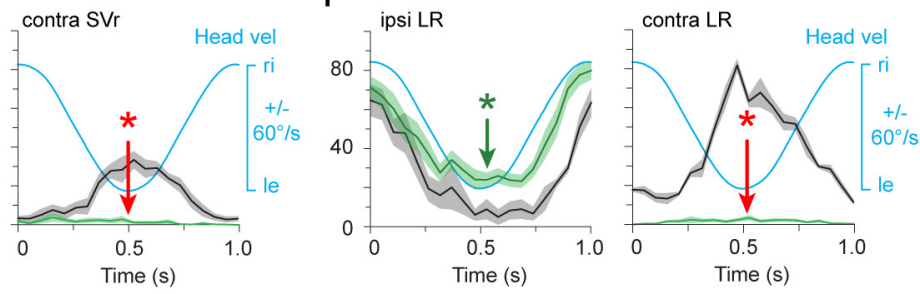

G

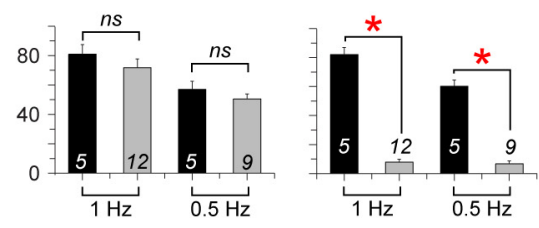

Figure 3. Postlesional changes of SVr and extraocular motor activity during vertical-axis vestibular stimulation in stage 55-57 Xenopus tadpoles. $A$, Computer-controlled two-axis turntable $\left(\boldsymbol{A}_{1}\right)$ allowed sinusoidal rotations around vertical $\left(\boldsymbol{A}_{1}\right.$, bottom) and horizontal axis of semi-intact preparations from control animals and after a UL on the left side $\left(\boldsymbol{A}_{2}\right)$. $\boldsymbol{B}-\boldsymbol{G}$, Spike discharge and firing rate modulation of an $\operatorname{SVr}(\boldsymbol{B})$ and $L R(\boldsymbol{E})$ on the ipsilesional side (left columns) and contralesional side (right columns) during sinusoidal head rotation at $1 \mathrm{~Hz}$ ( $\pm 60^{\circ} / \mathrm{s}$; blue traces; Head ${ }_{\text {vel }}$ ) in a control (no lesion, black traces) and 6 weeks post-UL (green traces). Mean discharge rate over one cycle $(n=30 ; \pm S E$; shaded area in each plot) of the ipsilesional and contralesional SVr $(\boldsymbol{C})$ and LR $(\boldsymbol{F})$ in

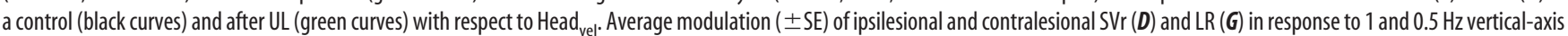
sinusoidal head rotations, respectively. The significance of difference in the peak firing rate of the respective nerve roots between controls and the postlesional group was tested with the Mann-Whitney $U$ test for unpaired parameters $\left({ }^{*} p \leq 0.05\right.$; n.s.). The number of animals are indicated; ipsi, ipsilesional side; contra, contralesional side; ri, right, le, left; $I V^{\text {th }} V$, IV ${ }^{\text {th }}$ ventricle.

traces). This loss was permanent, as indicated by the significantly reduced multiple-unit SVr discharge modulation during verticalaxis rotation (mean $\pm \mathrm{SE}, 5.7 \pm 2.3$ spikes/s at $1 \mathrm{~Hz}, n=11 ; 3.0 \pm$ 1.2 spikes/s at $0.5 \mathrm{~Hz}, n=8$ ) and roll-axis stimulation (mean \pm SE, $0.9 \pm 0.3$ spikes $/ \mathrm{s} ; n=6$ ) with respect to controls ( $p \leq 0.05$; Mann-Whitney $U$ test) in the ipsilesional direction $15 \mathrm{~d}$ (data not shown) and 6 weeks postlesion (Fig. $3 C, D$, Fig. $4 B, C$ ). The results at the two postlesional survival periods were also independent of the specific developmental stage (55-57) at the day of the recording. In addition, the significant loss was independent of stimulus magnitude or frequency (Fig. $3 D$ ). In contrast, SVr activity and its modulation on the left, ipsilesional side was unaffected in terms of magnitude and dynamics after UL (Fig. $3 B$, Fig. $4 A_{1}$, green traces) and remained similar to that of controls 6 weeks postlesion (n.s., Mann-Whitney $U$ test; Fig. $3 D, G$, Fig. 4C). The permanent, significant reduction of semicircular canal and otolith-evoked discharge modulation in contralesional SVrs without any obvious recovery suggests that the crossed excitatory influence of ipsilesional vestibular origin is irreversibly lost in these animals.
A general, persistent lack of excitatory influence from the operated side on motor responses on the contralesional side was confirmed by the simultaneous impairment of the vestibuloocular reflexes. In fact, the horizontal semicircular canal-related crossed excitation of abducens motoneurons, visible in controls as symmetric discharge modulation of the bilateral lateral rectus motor nerve with peak frequencies of $\sim 80$ spikes/s (Fig. $3 E$, black traces; mean \pm SE, $81.6 \pm 4.0$ spikes/s at $1 \mathrm{~Hz}, n=5 ; 59.6 \pm 8.0$ spikes/s at $0.5 \mathrm{~Hz}, n=5$ ) during horizontal rotations, became asymmetric (Fig. $3 E-F$, green traces) as indicated by the significantly reduced peak firing rate of the lateral rectus nerve on the right, contralesional side (mean $\pm \mathrm{SE}, 7.9 \pm 1.9$ spikes $/ \mathrm{s}$ at $1 \mathrm{~Hz}$, $n=12 ; 6.7 \pm 2.0$ spikes/s at $0.5 \mathrm{~Hz} ; n=9$ ) with respect to controls $(p \leq 0.05$, respectively; Mann-Whitney $U$ test; Fig. $3 G)$. Furthermore, this marked loss of crossed excitation (Fig. $3 F$, red asterisks in right plot) was accompanied by a simultaneous reduction of the uncrossed inhibition of abducens motoneurons on the left side during vertical-axis rotation in the ipsilesional direction (Fig. $3 F$, green asterisks in left plot). Therefore, vestibulomotor responses at both the spinal and brainstem level in Xenopus 6 weeks 

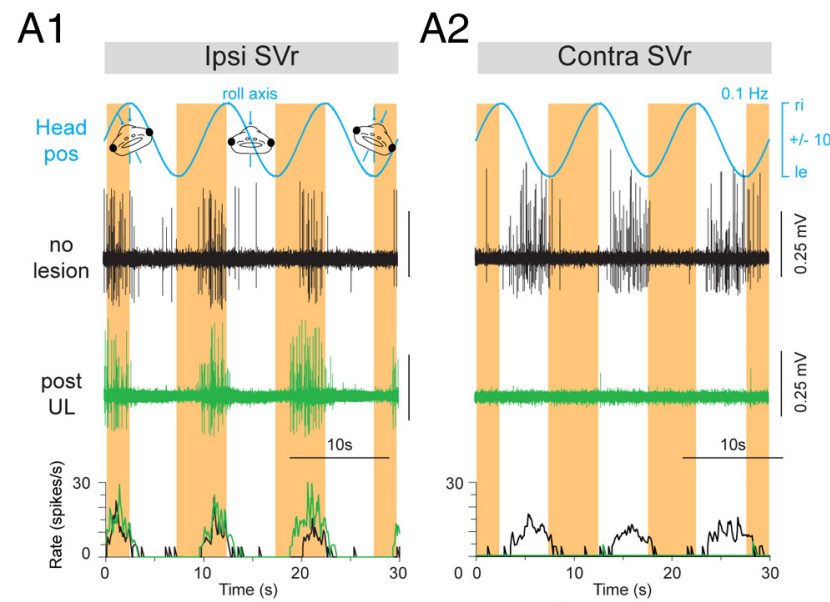

B

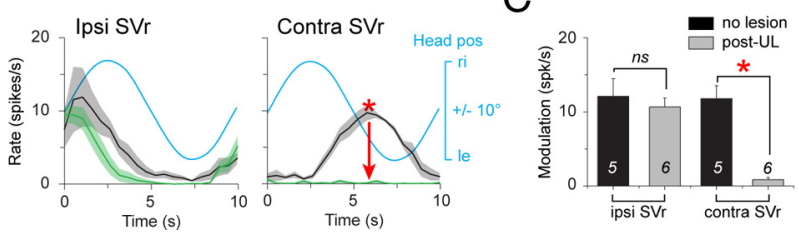

Figure 4. Postlesional changes of SVr activity during horizontal-axis vestibular stimulation in a stage 57 larval Xenopus. $A$, Spike discharge and firing rate modulation of the SVr on the ipsilateral side $\left(\boldsymbol{A}_{1}\right)$ and contralesional side $\left(\boldsymbol{A}_{2}\right)$ during sinusoidal left-right horizontal-axis head rotation (roll-axis) at $0.1 \mathrm{~Hz}$ ( $\pm 6 \%$; ; blue traces, Head $_{\text {pos }}$ ) in a control (no lesion, black traces) and 6 weeks post-UL (green traces). $\boldsymbol{B}$, Mean discharge rate over one cycle $(n=30$; $\pm \mathrm{SE}$; shaded area in each plot) of the ipsilesional and contralesional SVrin a control (black traces) and after UL (green traces) with respect to Head ${ }_{\text {pos }}$. C, Average modulation ( \pm SE) of ipsilesional and contralesional SVr during $0.1 \mathrm{~Hz}$ roll-axis sinusoidal rotations before $(n=5)$ and after $(n=6)$ UL. The significance of difference in the peak firing rate of the respective ispilesional and contralesional SVr between controls and the postlesional group was tested with the Mann-Whitney $U$ test for unpaired parameters ( ${ }^{*} p \leq 0.05 ; n$...$)$. ipsi indicates ipsilesional side; contra, contralesional side; ri, right, le, left; IV ${ }^{\text {th }} \mathrm{V}$, IV ${ }^{\text {th }}$ ventricle.

postlesion are characterized by a permanent loss of output from the ipsilesional vestibular nucleus, whereas the output from the vestibular nucleus on the intact side remains unaffected.

The persistent loss of activity after UL might be restricted to ipsilesional vestibular neurons or might be extended onto those postsynaptic spinal motoneurons that were characterized by absent vestibular discharge modulation during horizontal- or vertical-axis rotation. This was tested by recording the burst discharge of SVr's during spontaneous fictive swimming before (stage 57: $n=3$ ) and 6 weeks after UL (stage 57: $n=3$; Fig. 5). In control animals, spontaneous fictive swimming episodes in the absence of modulated sensory inputs consisted of sequences of alternating spike discharge bursts in SVr's on both sides (Fig. $\left.5 A_{1}, B\right)$. The peak rate of the bursts in the bilateral roots was symmetric and reached up to $\sim 90$ spikes/s (mean \pm SE, $90.3 \pm$ 1.7; $n=3$; left plot in Fig. $5 B$ ) at an average burst cycle frequency during the fictive swimming of $\sim 5 \mathrm{~Hz}$ (Fig. $5 C$ ). After UL, the characteristic alternating spinal motor discharge pattern during spontaneous fictive swimming in bilateral SVr's (Fig. $5 A_{2}, B$ ) remained unimpaired over the postlesional observation period. This is indicated by very similar (n.s., Wilcoxon signed-rank test) swim cycle frequencies (Fig. $5 C$ ) and peak firing rates of the SVr on the ipsilesional (mean \pm SE, $92.8 \pm 3.0 ; n=3$ ) and contralesional (mean $\pm \mathrm{SE}, 93.9 \pm 3.3 ; n=3$ ) side 6 weeks postlesion that remained unaltered compared with those of controls (n.s., Mann-Whitney $U$ test). This suggests that the permanent loss of vestibulomotor function is restricted to ipsilesional descending

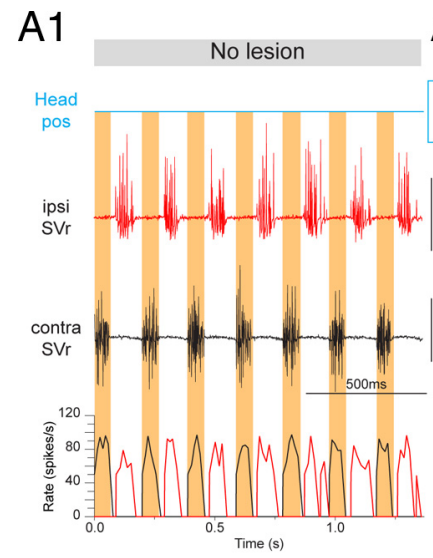

A2
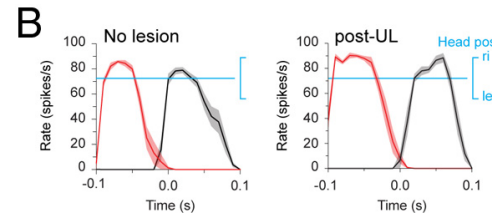

C

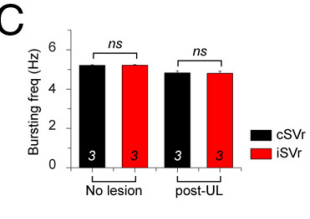

Figure 5. SVr discharge during a spontaneous fictive swimming sequence in stage 56 larval Xenopus before and after UL. A, Spike discharge and firing rate modulation of the SVr on the ipsilesional side (red traces) and contralesional side (black traces) during fictive swimming in a control $\left(\boldsymbol{A}_{1}\right.$, no lesion) and 6 weeks post-UL $\left(\boldsymbol{A}_{2}\right)$. $\boldsymbol{B}$, Mean discharge rate of swimming-related bursts over one swim cycle ( $n=20$; \pm SE; shaded area in each plot) of the ipsilesional (red traces) and contralesional (black traces) SVr in a control and after UL. C, Average ( \pm SE) burst frequency of ispilesional and contralesional SVr nerves before $(n=3)$ and after $(n=3) \mathrm{UL}$ revealed no difference between the two sides, respectively (Wilcoxon signed-rank test for paired parameters; $n$.s.). ipsi indicates ipsilesional side; contra, contralesional side; ri, right, le, left; i/cSVr, ipsi/contra SVr.

brainstem circuitries, leaving all downstream spinal interneuronal and motoneuronal target elements essentially unaffected.

\section{Degeneration of vestibular afferents and loss of vestibulospinal neurons after UL}

A potential neuronal loss after UL was evaluated by systematic tract tracing of the individual components that comprise the pathway between the vestibular end organs and spinal motoneurons. The evaluation was facilitated by the well established organization of semicircular canal and otolith afferent terminations in the brainstem and the known segmental arrangement of vestibulomotor projections (Straka et al., 2001). The anatomical arrangement of the vestibular end organs within the cartilaginous capsule allowed visually controlled postganglionic lesions that consisted of a lesion of all labyrinthine end organs along with the ganglion of Scarpa (Fig. $6 A_{1}, A_{2}$ ). The complete removal of all semicircular canal and otolith organs on the operated side (Fig. $6 A_{1}, A_{2}$, red asterisk) was confirmed by a comparison with the remaining peripheral sensory components and nerve branches in the otic capsule on the intact side $7 \mathrm{~d}$ after the lesion (Fig. $6 A_{3}$ ) in animals at stage $55(n=4)$. As a consequence of the UL, the VIII ${ }^{\text {th }}$ nerve, including the ganglion of Scarpa on the ipsilesional side, disappeared gradually (Fig. $6 A_{2}$, ar) during the first postlesional week.

A lesion-induced degeneration and apparent loss of vestibular nerve afferent fibers and central terminations in the vestibular nuclei after UL in larval Xenopus was substantiated by tracer application to the stump of the VIII ${ }^{\text {th }}$ nerve at the entry into the brainstem after various postlesional periods (Fig. $6 A_{1}$, inj). Seven days postlesion (at stage $55 ; n=4$ ), the overall number of labeled fibers within the remaining stump of the VIII ${ }^{\text {th }}$ nerve and the central axonal projection to the vestibular nuclei was consider- 

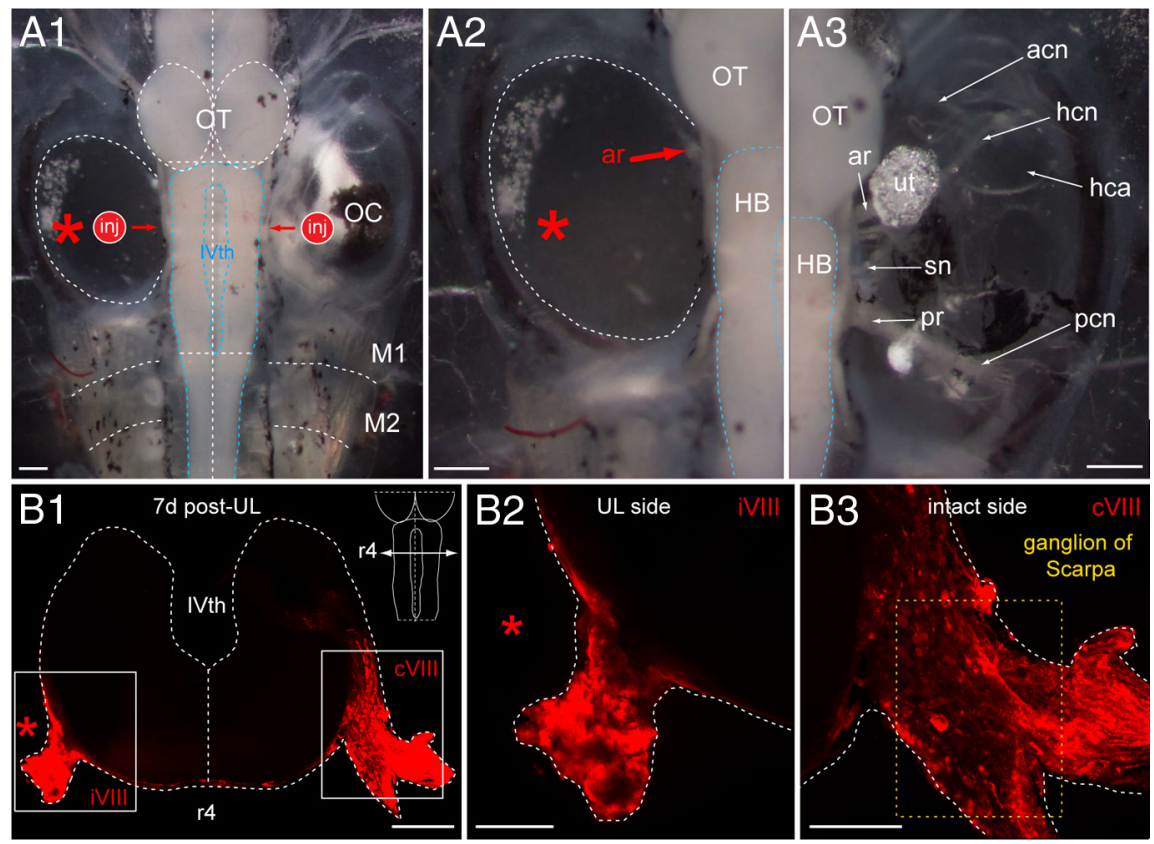

Figure 6. Morphological consequences of UL on VIII ${ }^{\text {th }}$ nerve afferent fibers in a stage 55 Xenopus tadpole. A, Dorsal view of the brainstem/spinal cord and bilateral otic capsules $\left(\boldsymbol{A}_{1}\right) 7 \mathrm{~d}$ after a UL on the left side (red asterisk) along with an indication of the sites of fluorescent tracer application (inj) to the severed, left and intact, right VIII th nerve; higher magnification of the otic capsules on both sides illustrate the absence of all labyrinthine end organs on the operated $\left(\boldsymbol{A}_{2}\right)$ and their presence on the intact side $\left(\boldsymbol{A}_{3}\right)$. $\boldsymbol{B}$, Confocal reconstruction of a cross-section through the hindbrain at $r 4$ (schematic inset in $\boldsymbol{B}_{1}$ ) depicting vestibular nerve afferent fibers on both sides at the entrance of the anterior branch (ar) of the VIII ${ }^{\text {th }}$ nerve into the brainstem $7 \mathrm{~d}$ postlesion; fibers were labeled after tracer application to the nerve stump on the operated side and the respective location on the intact side $\left(\boldsymbol{A}_{1}\right.$, inj); higher magnification of the outlined areas in $\boldsymbol{B}_{1}$ illustrating the reduction of labeled fibers on the operated $\left(\boldsymbol{B}_{2}\right)$ with respect to the intact $\left(\boldsymbol{B}_{3}\right)$ side. HB indicates hindbrain; $0 \mathrm{O}$, optic tectum; M1-2, myotome $1-2 ; \mathrm{IV}^{\text {th }}, \mathrm{IV}^{\text {th }}$ ventricle; ar and pr, anterior and posterior branch of the VIII ${ }^{\text {th }}$ nerve; acn, pcn, and hen, anterior, posterior, and horizontal semicircular canal nerve; hea, horizontal semicircular canal ampulla; sn, saccular nerve; ut, utricle; iVIII and cVIII, ipsilesional and contralesional VIII ${ }^{\text {th }}$ nerve. Scale bar in $\boldsymbol{A}_{1}-\boldsymbol{A}_{3}$ represents $300 \mu \mathrm{m}$; in $\boldsymbol{B}_{1}, 200 \mu \mathrm{m}$; and in $\boldsymbol{B}_{2}, \boldsymbol{B}_{3}, 100 \mu \mathrm{m}$, respectively.

ably reduced on the operated side (Fig. $6 B_{1}, B_{2}$, iVIII on the UL side), whereas tracer application to the intact VIII ${ }^{\text {th }}$ nerve labeled cell bodies in the ganglion of Scarpa and dense bundles of fibers (Fig. $6 B_{1}, B_{3}$, cVIII on the intact side) that projected toward the vestibular nuclei and ramified in the dorsolateral area of the hindbrain between hindbrain segments $\mathrm{r} 1$ and $\mathrm{r} 8$ (Fig. $7 A_{1}$ ). The observed loss of ipsilesional afferent terminations in the vestibular nuclei after UL with respect to controls was progressive, beginning $1 \mathrm{~d}$ postlesion (stage $55 ; n=3$ ) as seen by the reduced density of retrogradely labeled fibers (Fig. $7 B_{1}, B_{2}$, left) and was essentially complete $7 \mathrm{~d}$ postlesion ( Fig. $7 C_{1}, C_{2}, D_{1}, D_{2}$, sparse redlabeled fibers on the left). This loss of labyrinthine afferent input and the degeneration of afferent fibers might also impair a survival of the postsynaptic central vestibular neurons.

The anatomical organization of vestibulospinal neurons within the rhombomeric scaffold and a distinction into morphological subgroups based on somatic location and axonal projection (Straka et al., 2001) was made after bilateral retrograde labeling of these neurons from the upper spinal cord with different fluorescent tracers (stage 55: $n=6$; stage $56: n=8$; stage 57 : $n=7$; Fig. 7, Fig. 8). Independent of developmental stage, vestibulospinal neurons in controls $(n=9)$ were distinguished into three subgroups with distinct segmental locations and ipsilateral or contralateral descending axonal pathways, respectively (Fig. $7 D$, Fig. $8 B, C)$. A first, rostrally located vestibulospinal cell group (RVS) of 4-10 (mean \pm SE, $6.3 \pm 0.7 ; n=9$ ), relatively large neurons with characteristic long lateral-projecting dendrites coincided with the $\mathrm{r} 2-3$ portion of the vestibular nucleus (Fig. $\left.8 B_{1}, B_{2}, C\right)$. These neurons had axons that crossed the midline within the same segment as the parent cell body and descended toward the spinal cord in the contralateral medial longitudinal fascicle. A second, contralaterally projecting, relatively large and homogenous cell group of $60-85$ vestibulospinal neurons (mean \pm SE, $72.7 \pm 2.7 ; n=9$ ) originated mainly from $\mathrm{r} 5$, with few cell bodies in $\mathrm{r} 6$ (Fig. $7 A-C, D_{2}$, Fig. $8 B_{1}, B_{3}$ ), and coincided with the tangential vestibular nucleus (TAN; Straka et al., 2001). The axons of these neurons crossed the midline mainly in $\mathrm{r} 5$ to descend in the contralateral medial longitudinal fascicle along with the ipsilaterally projecting axons of the RVS neuronal subgroup. These two populations were supplemented by a third, large group of 70-130 neurons with uncrossed descending projections (mean \pm SE, $101.8 \pm 6.6 ; n=9$ ) that were distributed in the vestibular nuclei from $\mathrm{r} 3$ to $\mathrm{r} 6$ (Fig. $7 D_{1}, D_{2}$, Fig. $8 B_{1}, B_{4}$ ). Based on axonal trajectory and developmental origin (Fig. 8C), this population coincides with the vestibular subgroup that forms the lateral vestibulospinal tract in vertebrates (Glover, 1993). In addition, bilateral tracer application to the spinal cord retrogradely labeled a single large Mauthner neuron on each side in $\mathrm{r} 4$ with a contralaterally descending axon (Figs. $7 A_{1}-D_{1}$, Fig. $8 B_{1}, C$ ). Furthermore, sets of segmentally iterated reticulospinal neurons (Fig. $8 B_{1}, C$ ) with ipsilateral or contralateral projections (iRet, cRet) were identified that formed a long, medially located cell column from r1 to r8 (Fig. 8C), as described previously in the tadpoles of ranid frogs (Straka et al., 2001).

After UL, the overall pattern of segmentally arranged vestibulospinal and reticulospinal cell groups in the hindbrain was very similar to controls (Fig. 8), however, the number of retrogradely labeled vestibulospinal neurons in the different subgroups were differentially affected. Considerably fewer labeled cells were encountered in the ipsilesional TAN, both $15 \mathrm{~d}$ (stage 55: $n=2$, stage $56: n=2$, stage $57: n=2$; Fig. $8 D_{1}$ ) and 6 weeks (stage 56 : $n=3$, stage $57: n=3$; Fig. $8 E_{1}$ ) after the lesion compared with the corresponding intact side, respectively, which contained similar numbers of retrogradely labeled neurons as control animals (Fig. $\left.8 D_{2}, E_{2}\right)$. This reduction in ipsilesional TAN neurons after UL was significant (Fig. $8 F_{1}$ ) both with respect to the contralesional side ( $p \leq 0.05$; Wilcoxon signed-rank test) and with respect to controls ( $p \leq 0.05$; Mann-Whitney $U$ test) and corresponded to a loss of $\sim 45 \%$ and $\sim 60 \%$ of vestibulospinal neurons in the TAN $15 \mathrm{~d}$ and 6 weeks postlesion, respectively $\left(\right.$ Fig. $8 F_{1}$ ). In contrast to this clear loss of neurons, cell numbers in the lateral vestibulospinal tract and RVS subgroups (Fig. $8 F_{2}, F_{3}$ ) on the ipsilesional side remained similar to those on the intact side (n.s., Wilcoxon signed-rank test) and to those of controls (n.s., Mann-Whitney $U$ test). Even though vestibulospinal neurons in the RVS appeared to become fewer $15 \mathrm{~d}$ after the lesion, this reduction was not significant and was likely due to fluctuations and statistical variations in the extent of retrograde labeling of this generally small cell group (Fig. $8 F_{3}$ ). 

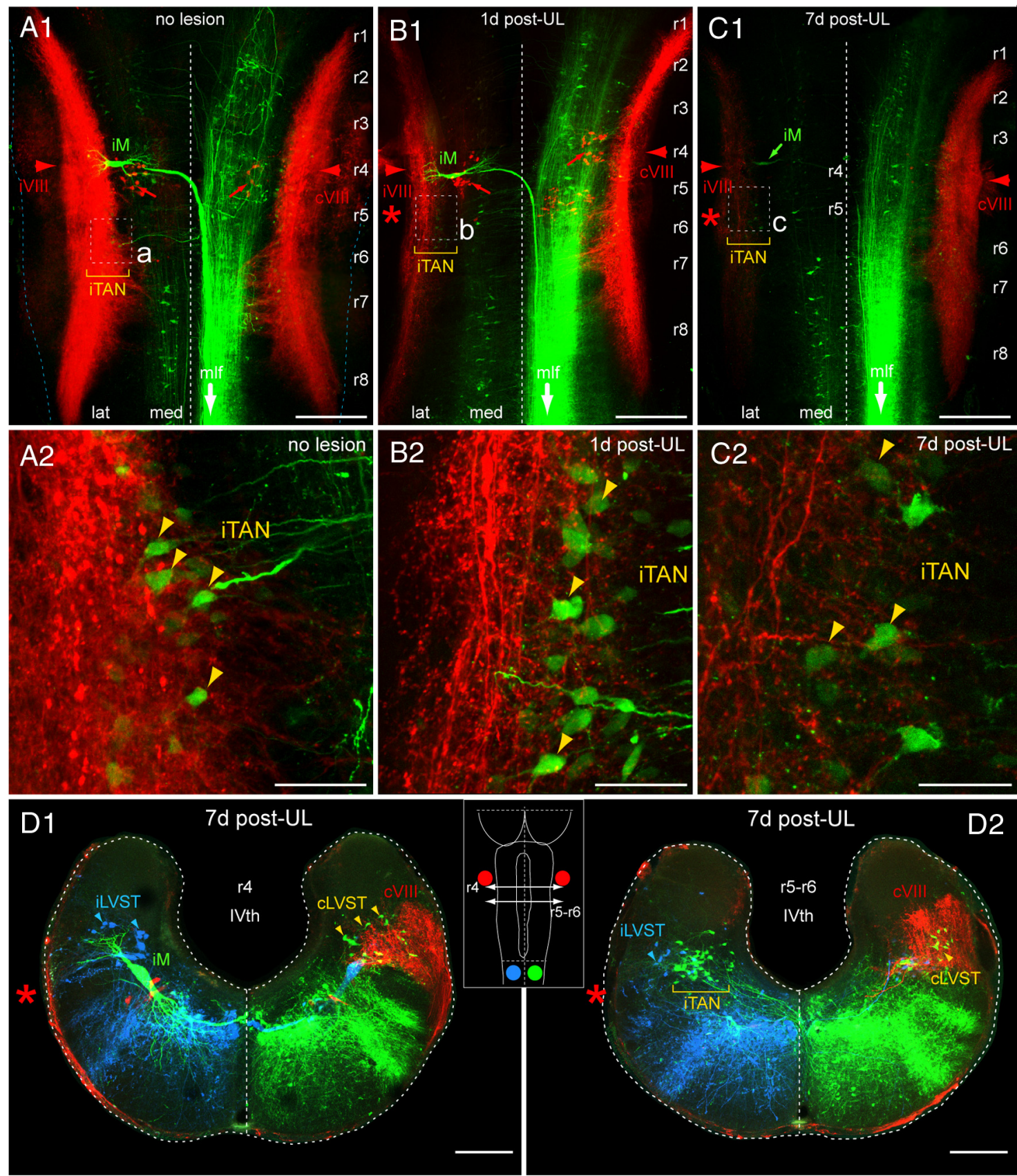

7d post-UL

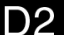

Figure 7. Postlesional loss of vestibular nerve afferent terminations in the vestibular nuclei after UL. $\boldsymbol{A}-\boldsymbol{C}$, Confocal reconstructions of hindbrain whole-mount preparations of stage $55-56$ Xenopus tadpoles showing labeled vestibular afferent terminations on both sides (red, Alexa Fluor 546 dextran) along with contralateral-projecting vestibulo and reticulospinal neurons (green, Alexa Fluor 488 dextran) in controls ( $\boldsymbol{A}$, no lesion), $1 \mathrm{~d}(\boldsymbol{B})$, and $7 \mathrm{~d}(\boldsymbol{C})$ post-UL; higher magnification of the ipsilesional TAN (iTAN; outlined areas in $\left.\boldsymbol{A}_{1}-\boldsymbol{C}_{1}\right)$ that forms a major subgroup of vestibulospinal neurons (yellow arrowheads), illustrating the successive loss of afferent fibers and terminations on the operated side after UL $\left(\boldsymbol{B}_{2}, \boldsymbol{C}_{2}\right)$ with respect to controls $\left(\boldsymbol{A}_{2}\right)$. $\boldsymbol{D}$, Confocal reconstruction of cross-sections of the hindbrain at $r 4\left(\boldsymbol{D}_{1}\right)$ and $\mathrm{r} 5-\mathrm{r} 6\left(\boldsymbol{D}_{2}\right) 7 \mathrm{~d}$ after $\mathrm{UL}$ on the left side (red asterisks) depicting the location of the Mauthner neuron (M), vestibulospinal neurons that descend in the lateral vestibulospinal tract (LVST), and vestibulospinal neurons in the TAN along with labeled vestibular afferent fibers (red VIII); the schematic inset illustrates the rostrocaudal hindbrain level of the cross-sections, the respective sites of tracer application on the left (blue, Alexa Fluor 647 dextran) and on the right side (green, Alexa Fluor 488 dextran) of the upper spinal cord, and tracer application to the bilateral VIII ${ }^{\text {th }}$ nerve (red, Alexa Fluor 546 dextran). Scale bar in $\boldsymbol{A}_{1}-\boldsymbol{C}_{1}$ represents $250 \mu \mathrm{m}$, in $\boldsymbol{A}_{2}-\boldsymbol{C}_{2} 50 \mu \mathrm{m}$ and in $\boldsymbol{D}_{1,2} 200 \mu \mathrm{m}$. IV ${ }^{\text {th }}$, IV ${ }^{\text {th }}$ ventricle; i, ipsilesional side; $\boldsymbol{C}_{\text {, }}$ contralesional side; $r 1-8$, rhombomere $1-8$.

The substantial loss of vestibulospinal neurons with crossed descending projections from a specific vestibular subgroup after UL corroborates earlier findings in Xenopus after UL (Rayer and Horn, 1986) and is consistent with a permanently decreased excitatory influence on spinal motoneurons on the contralesional side. Given the importance of the TAN as gravitoinertial relay center (Suwa et al., 1999), it is conceivable that part of the persistent descending imbalance in tonic and dynamic activity during vestibular stimulation is due to the loss of a considerable number of vestibulospinal neurons in this nucleus.

\section{Discussion}

UL in larval Xenopus provokes a severe postural and locomotor syndrome that is paralleled by a progressive deformation of the cartilaginous structural elements and subsequent consolidation by skeletal ossification. The likely causal link between UL and 

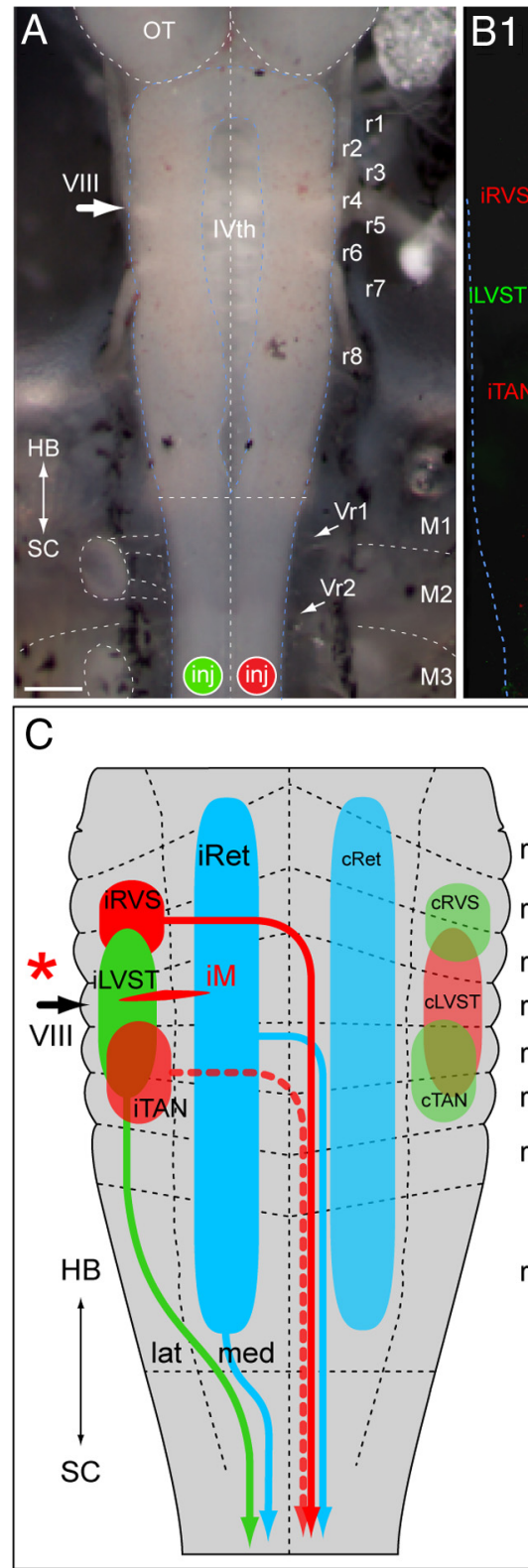

F1

TAN

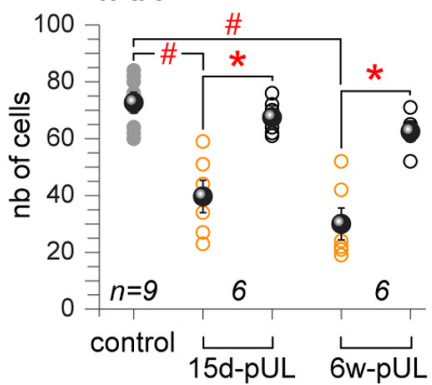

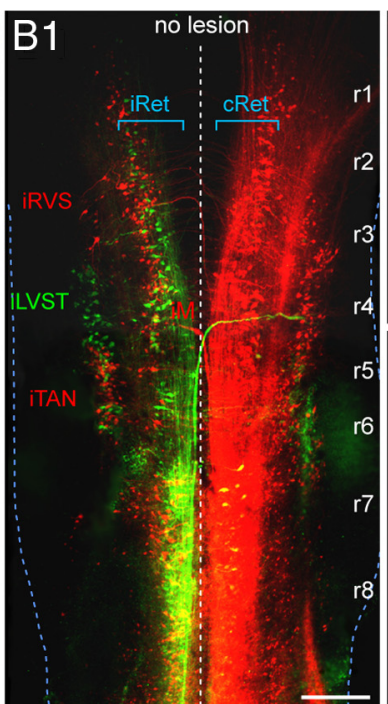

B2
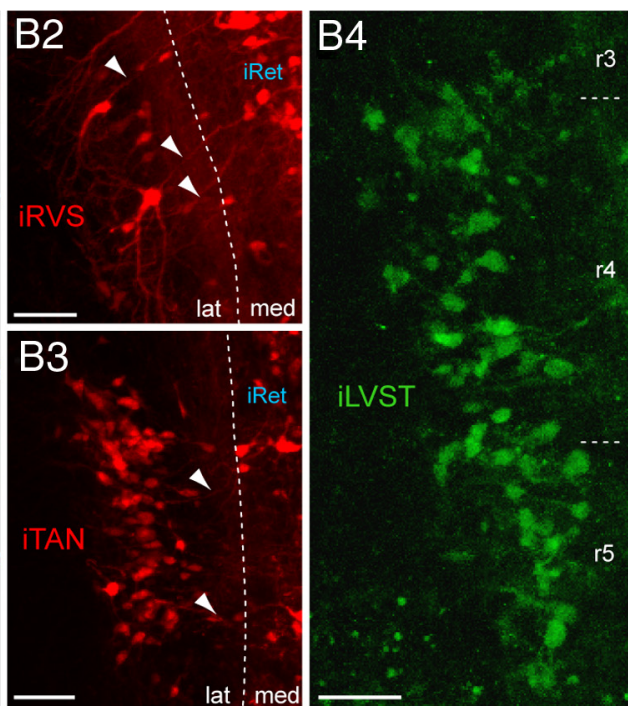

15d post-UL

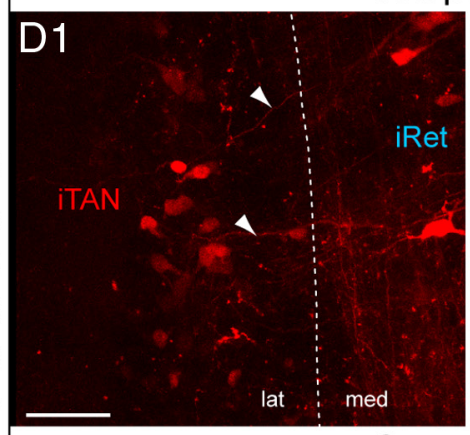

6w post-UL

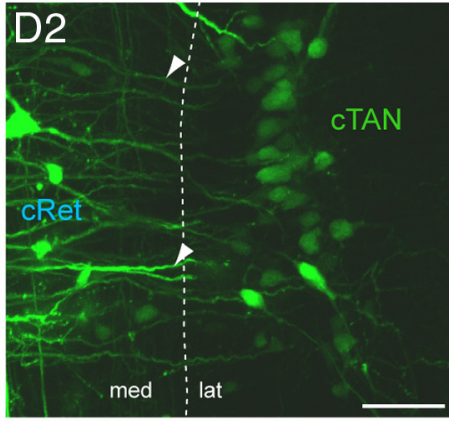

8
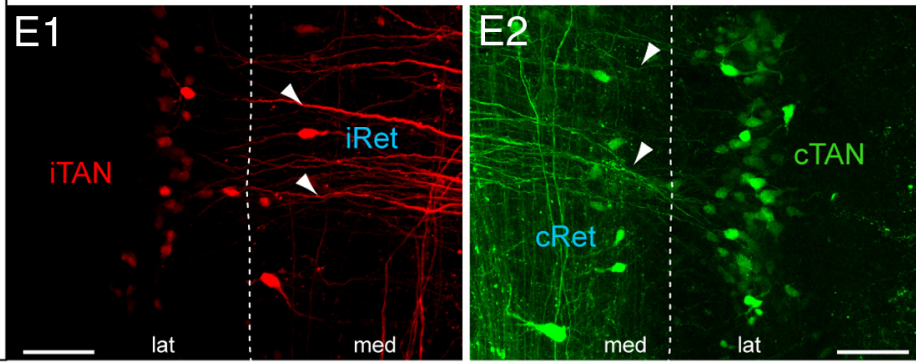

F3
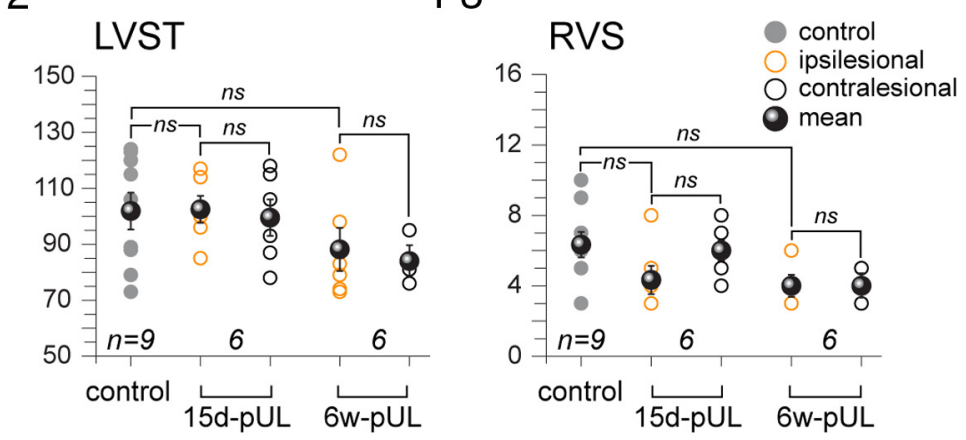

Figure 8. Loss of vestibulospinal neurons after UL in stage 55-57 Xenopus tadpoles. A, Photomicrograph of the hindbrain (HB) and rostral spinal cord (SC) depicting the sites of application of Alexa Fluor 488 dextran (inj, green) and of Alexa Fluor 546 dextran (inj, red) to the left and right upper spinal cord, respectively, in controls and $15 \mathrm{~d}$ and 6 weeks ( $6 \mathrm{~W}$ ) after $\mathrm{UL}$ on the left side. $\boldsymbol{B}$, Confocal reconstruction of bilateral spinal-projecting neurons in the hindbrain of a control animal ( $\boldsymbol{B}_{1}$, no lesion) illustrating the 3 major vestibulospinal cell groups with ipsilateral (i) or contralateral (c) axonal trajectories; higher magnification of retrogradely labeled neurons in the left vestibular nucleus that distinguish into a RVS $\left(\boldsymbol{B}_{2}\right)$ and TAN $\left(\boldsymbol{B}_{3}\right)$, both with crossed projections (labeled in red), respectively, and a third subgroup that gives rise to the uncrossed (labeled in green) lateral vestibulospinal tract (LVST, $\boldsymbol{B}_{4}$ ). $\boldsymbol{C}$, Summary depicting the segmental organization along 1 -r 8 and axonal trajectories of the 3 major vestibulospinal subgroups, the Mauthner cell (M) and the bilateral, segmentally iterated reticulospinal neurons (iRet, cRet) on the ipsilesional side (red asterisk) and contralesional side. $\boldsymbol{D}, \boldsymbol{E}_{1}$ Confocal reconstructions of TAN neurons with midline-crossing descending axons on the ipsilesional side (iTAN; $\left.\boldsymbol{D}_{1}, \boldsymbol{E}_{1}\right)$ and contralesional side ( $\left(\boldsymbol{C T A N}_{2} \boldsymbol{D}_{2}, \boldsymbol{E}_{2}\right)$ side $15 \mathrm{~d}(\boldsymbol{D})$ and 6 weeks $(\boldsymbol{E}, 6 \mathrm{~W})$ after UL; TAN neurons on the two sides of the brainstem were retrogradely labeled after unilateral application of two different tracers to the two sides of the upper spinal cord ( $\boldsymbol{A}$, inj). $\boldsymbol{F}$, Numbers (mean \pm SE) of retrogradely labeled neurons in the TAN $\left(\boldsymbol{F}_{1}\right)$, LVST $\left(\boldsymbol{F}_{2}\right)$, and RVS $\left(\boldsymbol{F}_{3}\right)$ subgroups of controls and on the ispilesional and contralesional side of (Figure legend continues.) 
scoliotic-like deformations is the induction of a continuous imbalanced activity in crossed vestibular descending pathways to contralesional spinal motoneurons. This loss of activity concurs with the bilateral imbalance in axial muscle tension and its consequence for the skeletal arrangement.

\section{Behavioral consequences of UL}

After UL, lesion-induced postural and limb asymmetries generally recover more or less completely over a species-specific period in all terrestrial vertebrates by a process called "vestibular compensation" (Dieringer, 1995; Peusner et al., 2012). The underlying mechanism is a distributed process at multiple sites in the brainstem and spinal cord (Llinás and Walton, 1979) and includes cellular and network plasticity (Dieringer, 1995; Dutia, 2010; Beraneck and Idoux, 2012) and sensory substitution with motion- and posture-related signals from other modalities (Dieringer, 2003). At variance with the reported postural recovery after UL in terrestrial vertebrates and the obvious absence of skeletal deformations (de Waele et al., 1989), the impaired locomotor activity and asymmetric posture remains more or less permanent in Xenopus (Fig. 1B,C; Rayer et al., 1983) provided the lesion was performed in older larvae or adults (Horn, 1981). Although the successful vestibular compensation after UL in young Xenopus tadpoles ( stage 46 ) is likely due to the developmental plasticity during vestibular nuclei formation (Horn, 1981; Rayer and Horn, 1986), the essential persistence of locomotor and postural deficits after UL in older tadpoles or adults might be related to the aquatic lifestyle that restricts the possibility for gravity-related sensory substitution of vestibular deficits (Lambert and Straka, 2012).

In adult grass frogs, the postural recovery after UL is paralleled by an increased synaptic efficacy in propriospinal circuitries (Straka and Dieringer, 1995), asymmetrically enhanced neck reflexes (Kolb, 1955), and potentially by a higher sensitivity of proprioceptive sensation. Therefore, substitution of absent vestibular inputs by signals related to limb proprioception at the brainstem (Dieringer et al., 1984) and spinal levels appear to be essential for the postural recovery (Lambert and Straka, 2012). These sensory signals, which are generally available in all terrestrial vertebrates, likely provide a supplemental reference frame that allows the assumption of a normal body position. Accordingly, the poor postural recovery after UL in Xenopus (Fig. 1C; Horn, 1981) and the concurrent manifestation of skeletal deformations after a lesion at late larval stages (Fig. $1 D$, Fig. $2 A_{2}-C_{2}$ ) are compatible with the restricted availability to use these inputs for sensory substitution in an aquatic habitat. Therefore, for aquatic amphibian larvae, the buoyancy of the body in water, the delayed limb development, the absence of spinal dorsal roots in tadpoles (Nordlander et al., 1988), and the horizontally extended limbs in the permanently aquatic adult Xenopus (Fig. 1C) considerably restricts the use of proprioceptive signals as auxiliary reference frame for postural recalibration after UL. In the absence of

\section{$\leftarrow$}

(Figure legend continued.) animals $15 \mathrm{~d}$ and 6 weeks $(6 \mathrm{w})$ postlesion; the number of labeled cells in the TAN $\left(\boldsymbol{F}_{1}\right)$ but not the LVST $\left(\boldsymbol{F}_{2}\right)$ or RVS $\left(\boldsymbol{F}_{3}\right)$ on the ipsilesional side was significantly reduced with respect to the contralesional side $15 \mathrm{~d}$ and 6 weeks postlesion $\left({ }^{*} p \leq 0.05\right.$; Wilcoxon signed-rank test for paired parameters; n.s.); with respect to controls, only the number of labeled cells in the TAN $\left(\boldsymbol{F}_{1}\right)$ but not the LVST $\left(\boldsymbol{F}_{2}\right)$ or RVS $\left(\boldsymbol{F}_{3}\right)$ on the ipsilesional side was significantly reduced ( ${ }^{\#} p \leq 0.05$; Mann-Whitney $U$ test for unpaired parameters; $n . s$.); $n$ indicates the number of animals in each group; $\mathrm{IV}^{\text {th }}, \mathrm{IV}^{\text {th }}$ ventricle; lat, lateral; med, medial; $0 \mathrm{~T}$, optic tectum; M1-3, myotomes 1-3; Vr, SVr. Scale bars in $\boldsymbol{A}$ represent $300 \mu \mathrm{m} ; \boldsymbol{B}_{1}, 200 \mu \mathrm{m}$; $B_{2}-B_{4}, D_{1}, D_{2}, E_{1}, E_{2}, 50 \mu \mathrm{m}$. an antigravitational muscle tone for postural stability that generates respective limb-proprioceptive inputs, an imbalanced descending tone will persist and likely cause the observed skeletal deformations. Therefore, our prediction is that a UL in amphibian larvae performed at a more advanced developmental stage (Horn, 1981) might cause poor compensation and induce similar scoliotic deformations as in Xenopus despite a subsequent terrestrial ecophysiology in, for example, adult grass frogs or toads.

\section{Causality between UL and scoliotic deformations}

Even though the lack of limb proprioceptive signals at various levels of the CNS appears to be essential for inducing scoliotic deformations in Xenopus after UL, additional reaction mechanisms likely facilitate the manifestation of the provoked asymmetric posture. However, the disappearance of central vestibular neurons after UL in Xenopus tadpoles (Fig. 8F $F_{1}$ ), consistent with earlier reports (Rayer and Horn, 1986), is independent of the preceding VIII ${ }^{\text {th }}$ nerve degeneration (Fig. $6 A_{1}, A_{2}, B_{1}, B_{2}$, Fig. $\left.7 C_{1}, C_{2}, D_{1}, D_{2}\right)$, because a similar postganglionic lesion in adult grass frogs also causes afferent degeneration, although without obvious loss of central neurons (Kunkel and Dieringer, 1994). The disappearance of a particular set of crossed excitatory descending vestibular neurons in Xenopus (Fig. $8 D_{1}, E_{1}$ ) might be related to the absence of spinal dorsal roots and the respective ascending projections in tadpoles (Nordlander et al., 1988) and thus to the lack of limb proprioceptive inputs at the brainstem level. In fact, these latter inputs are specifically augmented after $\mathrm{UL}$, as demonstrated by the increased projection of ascending dorsal root fibers to the ipsilesional vestibular nuclei in grass frogs (Dieringer et al., 1984), in which no neuronal loss is observed. Such a sensory substitution complies with the observed facilitation of existing and recruitment of new excitatory inputs by vestibular neurons after a specific peripheral lesion (Goto et al., 2000, 2001; Rohregger and Dieringer, 2003), potentially preventing apoptotic reactions (Dieringer, 2003).

The disappearance of tangential vestibular neurons (Fig. $8 D_{1}-$ $F_{1}$ ) as the major graviceptive relay nucleus (Suwa et al., 1999), consistent with earlier observations (Rayer and Horn, 1986), facilitates a bilateral imbalance of descending activity and spinal motoneuronal drive after the loss of one labyrinth (Fig. 3B, Fig. $4 A_{2}$ ) and causes a permanent asymmetric tone of axial and limb muscles. Because the motoneurons continue to provide a symmetric output during spinal pattern generator-derived locomotor activity (fictive swimming) after UL (Fig. $5 A_{2}$ ), the permanent postural asymmetry likely originates from a continuous premotor imbalance, rather than impaired motoneuronal properties. The persistent vestibulomotor imbalance, however, is not restricted to the spinal motor system, but is more general and includes vestibuloocular connections given the failure to reestablish an excitatory modulation of contralesional abducens motoneurons (Fig. 3E) in larval Xenopus. This is at variance with adult terrestrial grass frogs, which improve vestibuloocular reflexes after UL in parallel with the postural recovery (Agosti et al., 1986).

\section{Common principles for the induction of scoliosis in animal models and humans}

The morphophysiological circumstances under which skeletal deformations were induced after UL in larval Xenopus (Fig. 1D) potentially allows localizing prerequisites for triggering scoliotic deformations in other animals and in humans. Although vestibulomotor deficits are the apparent origin in Xenopus, any uncompensated bilateral imbalance in descending projections could 
provoke tonic asymmetric muscle contractions and an abnormal pulling at skeletal elements. This sequence of events might reconcile the different experimental scoliosis models, such as medullary lesions of proprioceptive pathways in rabbits (Barrios et al., 1987), selective lesions of brainstem nuclei involved in mediating premotor signals to the spinal cord in normal rats (Barrios and Arrotegui, 1992), or pinealectomy in chickens (O'Kelly et al., 1999; Akel et al., 2009a) and bipedal rodents in which proprioceptive signals were absent or impaired by a surgical removal of the forelimbs (Machida et al., 2005; Akel et al., 2009b). Common to all models, including the recently established robo3 genetic model with disrupted crossing hindbrain projections (Jen, 2008; Renier et al., 2010), is a permanent asymmetric impairment of motor and posture control pathways, corroborating initial assumptions on the origin of human AIS (Tezuka, 1971; Yamada et al., 1984; Herman et al., 1985).

Uncompensated asymmetric motor control deficits, while necessary, are not sufficient, because a UL in adult Xenopus causes a permanent postural syndrome, although without inducing scoliotic deformations (Lambert et al., 2009). This suggests that the presence of cartilage or soft osseal tissue is required to provoke skeletal deformations under a constant asymmetric muscular pull. This is the case in larval amphibians, in which cartilaginous elements already exhibit deformations (Fig. $2 \mathrm{~A}_{2}, \mathrm{~B}, \mathrm{C}$ ) that are later manifested by the ossification process subsequent to the UL (Trueb and Hanken, 1992). This is comparable to the situation in human AIS, in which the first signs of scoliotic deformations are present in newborns (Lincoln, 2007), are further manifested by subsequent body growth, and are reinforced during adolescence when body and limbs grow particularly fast (Angevine and Deutsch, 2008). Therefore, for AIS, skeletal asymmetries are likely initiated during embryogenesis when all structural elements are still soft and reinforced by later ossification under a constant, asymmetric mechanical pull by motor imbalances.

Given the distinct sequences of spine patterning, the observed embryonic induction of scoliotic deformations in humans (Pourquié, 2011) due to potential bilateral asymmetric impairments of descending motor control pathways (Hostikka et al., 2009 ) is potentially facilitated by the floating position of the fetus that restricts using limb proprioceptive signals as an auxiliary reference frame for recalibration. The limited use of antigravitational limb proprioception in newborn babies during the first year (Assaiante et al., 2005) extends this period and allows initial deformations to further manifest. Consistent reports of vestibular deficits in AIS patients (Haumont et al., 2011; Shi et al., 2011), along with our previous and present findings in Xenopus, suggest that a tonic imbalance in descending utricular pathways (Wiener-Vacher and Mazda, 1998) might be a possible origin for the induction of skeletal deformations, compatible with the predominance of these signals for posture control in quadrupedal vertebrates (de Waele et al., 1989). However, any persistent asymmetry in descending pathways during vertebrate fetal brain development, whether initiated at the peripheral or central levels, should have a similar deteriorating impact on the deformable growing skeleton, thereby causing scoliotic deformations in adults.

\section{References}

Agosti R, Dieringer N, Precht W (1986) Partial restitution of lesion-induced deficits in the horizontal vestibulo-ocular reflex performance measured from the bilateral abducens motor output in frogs. Exp Brain Res 61:291302. Medline

Ahn UM, Ahn NU, Nallamshetty L, Buchowski JM, Rose PS, Miller NH,
Kostuik JP, Sponseller PD (2002) The etiology of adolescent idiopathic scoliosis. Am J Orthop 31:387-395. Medline

Akel I, Demirkiran G, Alanay A, Karahan S, Marcucio R, Acaroglu E (2009a) The effect of calmodulin antagonists on scoliosis: bipedal C57BL/6 mice model. Eur Spine J 18:499-505. CrossRef Medline

Akel I, Kocak O, Bozkurt G, Alanay A, Marcucio R, Acaroglu E (2009b) The effect of calmodulin antagonists on experimental scoliosis: a pinealectomized chicken model. Spine 34:533-538. CrossRef Medline

Angevine PD, Deutsch H (2008) Idiopathic scoliosis. Neurosurgery 63:8693. CrossRef Medline

Assaiante C, Mallau S, Viel S, Jover M, Schmitz C (2005) Development of postural control in healthy children: a functional approach. Neural Plast 12:109-118; discussion 263-272. CrossRef Medline

Barrios C, Arrotegui JI (1992) Experimental kyphoscoliosis induced in rats by selective brain stem damage. Int Orthop 16:146-151. Medline

Barrios C, Tuñón MT, De Salis JA, Beguiristain JL, Cañadell J (1987) Scoliosis induced by medullary damage: an experimental study in rabbits. Spine 12:433-439. CrossRef Medline

Beraneck M, Idoux E (2012) Reconsidering the role of neuronal intrinsic properties and neuromodulation in vestibular homeostasis. Front Neurol 3:25. CrossRef Medline

Böser S, Horn ER (2006) Hypergravity susceptibility of ventral root activity during fictive swimming in tadpoles (Xenopus laevis). Arch Ital Biol 144: 99-113. Medline

Burwell RG, Aujla RK, Grevitt MP, Dangerfield PH, Moulton A, Randell TL, Anderson SI (2009) Pathogenesis of adolescent idiopathic scoliosis in girls-a double neuro-osseous theory involving disharmony between two nervous systems, somatic and autonomic expressed in the spine and trunk: possible dependency on sympathetic nervous system and hormones with implications for medical therapy. Scoliosis 4:24. CrossRef Medline

Cheung KM, Wang T, Poon AM, Carl A, Tranmer B, Hu Y, Luk KD, Leong JC (2005) The effect of pinealectomy on scoliosis development in young nonhuman primates. Spine 30:2009-2013. CrossRef Medline

Cheung KM, Wang T, Qiu GX, Luk KD (2008) Recent advances in the aetiology of adolescent idiopathic scoliosis. Int Orthop 32:729-734. CrossRef Medline

Combes D, Merrywest SD, Simmers J, Sillar KT (2004) Developmental segregation of spinal networks driving axial- and hindlimb-based locomotion in metamorphosing Xenopus laevis. J Physiol 559:17-24. CrossRef Medline

De Waele C, Graf W, Josset P, Vidal PP (1989) A radiological analysis of the postural syndromes following hemilabyrinthectomy and selective canal and otolith lesions in the guinea pig. Exp Brain Res 77:166-182. Medline

Dieringer N (1995) 'Vestibular compensation': Neural plasticity and its relations to functional recovery after labyrinthine lesions in frogs and other vertebrates. Prog Neurobiol 46:97-129. CrossRef Medline

Dieringer N (2003) Activity-related postlesional vestibular reorganization. Ann N Y Acad Sci 1004:50-60. CrossRef Medline

Dieringer N, Künzle H, Precht W (1984) Increased projection of ascending dorsal root fibers to vestibular nuclei after hemilabyrinthectomy in the frog. Exp Brain Res 1984:574-578. Medline

Du SJ, Frenkel V, Kindschi G, Zohar Y (2001) Visualizing normal and defective bone development in zebrafish embryos using the fluorescent chromophore calcein. Dev Biol 238:239-246. CrossRef Medline

Dutia MB (2010) Mechanisms of vestibular compensation: recent advances. Curr Opin Otolaryngol Head Neck Surg 18:420-424. CrossRef Medline

Fagan AB, Kennaway DJ, Oakley AP (2009) Pinealectomy in the chicken: a good model of scoliosis? Eur Spine J 18:1154-1159. CrossRef Medline

Glover JC (1993) The development of brain stem projections to the spinal cord in the chicken embryo. Brain Res Bull 30:265-271. CrossRef Medline

Goto F, Straka H, Dieringer N (2000) Expansion of afferent vestibular signals after the section of one of the vestibular nerve branches. J Neurophysiol 84:581-584. Medline

Goto F, Straka H, Dieringer N (2001) Postlesional vestibular reorganization in frogs: Evidence for a basic reaction pattern after nerve injury. J Neurophysiol 85:2643-2646. Medline

Haumont T, Gauchard GC, Lascombes P, Perrin PP (2011) Postural instability in early-stage idiopathic scoliosis in adolescent girls. Spine 36:E847854. CrossRef Medline

Herman R, Mixon J, Fisher A, Maulucci R, Stuyck J (1985) Idiopathic scoliosis and the central nervous system: a motor control problem. The Har- 
rington lecture, 1983. Scoliosis Research Society. Spine 10:1-14. CrossRef Medline

Horn E (1981) An ontogenetic approach to vestibular compensation mechanisms. In: Lesion-induced neuronal plasticity in sensori-motor systems (Flohr H, Precht W, eds), pp 173-183. Berlin, Heidelberg, New York: Springer.

Horn E, Rayer B (1978) Compensation of vestibular lesions in relation to development. Naturwissenschaften 65:441. CrossRef Medline

Horn E, Lang HG, Rayer B (1986a) The development of the static vestibuloocular reflex in the Southern Clawed Toad, Xenopus laevis. I. Intact animals. J Comp Physiol A 159:869-878. CrossRef

Horn E, Mack R, Lang HG (1986b) The development of the static vestibuloocular reflex in the Southern Clawed Toad, Xenopus laevis. II. Animals with acute vestibular lesions. J Comp Physiol A 159:879-885. CrossRef Medline

Hostikka SL, Gong J, Carpenter EM (2009) Axial and appendicular skeletal transformations, ligament alterations, and motor neuron loss in Hoxc10 mutants. Int J Biol Sci 5:397-410. CrossRef Medline

Jen JC (2008) Effects of failure of development of crossing brainstem pathways on ocular motor control. Prog Brain Res 171:137-141. CrossRef Medline

Jensen GM, Wilson KB (1979) Horizontal postrotatory nystagmus response in female subjects with adolescent idiopathic scoliosis. Phys Ther 59: 1226-1233. Medline

Kolb E (1955) Untersuchungen über zentrale Kompensation und Kompensationsbewegungen einseitig entstateter Frösche. Z Vergl Physiol 37:136160. CrossRef

Kunkel AW, Dieringer N (1994) Morphological and electrophysiological consequences of unilateral pre- versus postganglionic vestibular lesions in the frog. J Comp Physiol A 174:621-632. Medline

Lambert FM, Straka H (2012) The frog vestibular system as a model for lesion-induced plasticity: basic neural principles and implications for posture control. Front Neurol 3:42. CrossRef Medline

Lambert FM, Beck JC, Baker R, Straka H (2008) Semicircular canal size determines the developmental onset of angular vestibuloocular reflexes in larval Xenopus. J Neurosci 28:8086-8095. CrossRef Medline

Lambert FM, Malinvaud D, Glaunès J, Bergot C, Straka H, Vidal PP (2009) Vestibular asymmetry as the cause of idiopathic scoliosis: a possible answer from Xenopus. J Neurosci 29:12477-12483. CrossRef Medline

Lambert FM, Combes D, Simmers J, Straka H (2012) Gaze stabilization by efference copy signaling without sensory feedback during vertebrate locomotion. Curr Biol 22:1649-1658. CrossRef Medline

Lincoln TL (2007) Infantile idiopathic scoliosis. Am J Orthop 36:586-590. Medline

Llinás R, Walton K (1979) Vestibular compensation: a distributed property of the central nervous system, in Integration in the Nervous System, eds. $\mathrm{H}$ Asanuma and VJ Wilson (Tokyo: Igaku Shoin), 145-166.

Machida M, Saito M, Dubousset J, Yamada T, Kimura J, Shibasaki K (2005) Pathological mechanism of idiopathic scoliosis: experimental scoliosis in pinealectomized rats. Eur Spine J 14:843-848. CrossRef Medline

Machida M, Dubousset J, Yamada T, Kimura J (2009) Serum melatonin levels in adolescent idiopathic scoliosis prediction and prevention for curve progression-a prospective study. J Pineal Res 46:344-348. CrossRef Medline

Mallau S, Bollini G, Jouve JL, Assaiante C (2007) Locomotor skills and balance strategies in adolescents idiopathic scoliosis. Spine 32:E14-E22. CrossRef Medline

Manzoni D, Miele F (2002) Vestibular mechanisms involved in idiopathic scoliosis. Arch Ital Biol 140:67-80. Medline

Moreau A, Wang DS, Forget S, Azeddine B, Angeloni D, Fraschini F, Labelle H, Poitras B, Rivard CH, Grimard G (2004) Melatonin signaling dysfunction in adolescent idiopathic scoliosis. Spine 29:1772-1781. CrossRef Medline

Nieuwkoop PD, Faber J (1994) Normal table of Xenopus laevis (Daudin): a systematical and chronological survey of the development from the fertilized egg till the end of metamorphosis. New York: Garland.
Nordlander RH, Awwiller DM, Cook H (1988) Dorsal roots are absent from the tail of larval Xenopus. Brain Res 440:391-395. CrossRef Medline

O’Kelly C, Wang X, Raso J, Moreau M, Mahood J, Zhao J, Bagnall K (1999) The production of scoliosis after pinealectomy in young chickens, rats, and hamsters. Spine 24:35-43. CrossRef Medline

Peusner KD, Shao M, Reddaway R, Hirsch JC (2012) Basic Concepts in understanding recovery of function in vestibular reflex networks during vestibular compensation. Front Neurol 3:17. CrossRef Medline

Pourquié O (2011) Vertebrate segmentation: From cyclic gene networks to scoliosis. Cell 145:650-663. CrossRef Medline

Rayer B, Horn E (1986) The development of the static vestibulo-ocular reflex in the Southern Clawed Toad, Xenopus laevis. III. Chronic hemilabyrinthectomized tadpoles. J Comp Physiol A 159:887-895. CrossRef Medline

Rayer B, Cagol E, Horn E (1983) Compensation of vestibular-induced deficits in relation to the development of the southern clawed toad, Xenopus laevis Daudin. J Comp Physiol A Neuroethol Sens Neural Behav Physiol 151:487-498. CrossRef

Renier N, Schonewille M, Giraudet F, Badura A, Tessier-Lavigne M, Avan P, De Zeeuw CI, Chédotal A (2010) Genetic dissection of the function of hindbrain axonal commissures. PLoS Biol. 8:e1000325. CrossRef Medline

Rohregger M, Dieringer N (2003) Postlesional vestibular reorganization improves the gain but impairs the spatial tuning of the maculo-ocular reflex in frogs. J Neurophysiol 90:3736-3749. CrossRef Medline

Rousie D, Hache JC, Pellerin P, Deroubaix JP, Van Tichelen P, Berthoz A (1999) Oculomotor, postural, and perceptual asymmetries associated with a common cause. Craniofacial asymmetries and asymmetries in vestibular organ anatomy. Ann N Y Acad Sci 871:439-446. CrossRef Medline

Sahlstrand T, Petruson B (1979) A study of labyrinthine function in patients with adolescent idiopathic scoliosis. I. An electro-nystagmographic study. Acta Orthop Scand 50:759-769. CrossRef Medline

Sahlstrand T, Petruson B, Ortengren R (1979) Vestibulospinal reflex activity in patients with adolescent idiopathic scoliosis. Postural effects during caloric labyrinthine stimulation recorded by stabilometry. Acta Orthop Scand 50:275-281. CrossRef Medline

Shi L, Wang D, Chu WC, Burwell GR, Wong TT, Heng PA, Cheng JC (2011) Automatic MRI segmentation and morphoanatomy analysis of the vestibular system in adolescent idiopathic scoliosis. Neuroimage 54 Suppl 1:S180-S188. CrossRef

Straka H, Dieringer N (1995) Spinal plasticity after hemilabyrinthectomy and its relation to postural recovery in the frog. J Neurophysiol 73:16171631. Medline

Straka H, Simmers J (2012) Xenopus laevis: an ideal experimental model for studying the developmental dynamics of neural network assembly and sensory-motor computations. Dev Neurobiol 72:649-663. CrossRef Medline

Straka H, Baker R, Gilland E (2001) Rhombomeric organization of vestibular pathways in larval frogs. J Comp Neurol 437:42-55. CrossRef Medline

Suwa H, Gilland E, Baker R (1999) Otolith ocular reflex function of the tangential nucleus in teleost fish. Ann N Y Acad Sci 871:1-14. CrossRef Medline

Tezuka A (1971) Development of scoliosis in cases with congenital organic abnormalities of the brain-stem. A report of 7 cases. Tokushima J Exp Med 18:49-62. Medline

Trueb L, Hanken J (1992) Skeletal development in Xenopus laevis (Anura: Pipidae). J Morphol 241:1-41. Medline

Weinstein SL, Dolan LA, Cheng JC, Danielsson A, Morcuende JA (2008) Adolescent idiopathic scoliosis. Lancet 371:1527-1537. CrossRef Medline

Wiener-Vacher SR, Mazda K (1998) Asymmetric otolith vestibulo-ocular responses in children with idiopathic scoliosis. J Pediatr 132:1028-1032. CrossRef Medline

Yamada K, Yamamoto H, Nakagawa Y, Tezuka A, Tamura T, Kawata S (1984) Etiology of idiopathic scoliosis. Clin Orthop Relat Res 184:50-57. Medline 